\title{
ADOLESCENTS IN CRISIS: A GEOGRAPHIC EXPLORATION OF HELP-SEEKING BEHAVIOR USING DATA FROM CRISIS TEXT LINE
}

\author{
A Thesis \\ by \\ LAURA KATHERINE THOMPSON
}

Submitted to the Graduate School

at Appalachian State University

in partial fulfillment of the requirements for the degree of MASTER OF ARTS

May 2018

Department of Geography and Planning 


\title{
ADOLESCENTS IN CRISIS: A GEOGRAPHIC EXPLORATION OF HELP-SEEKING BEHAVIOR USING DATA FROM CRISIS TEXT LINE
}

\author{
A Thesis \\ by \\ LAURA THOMPSON \\ May 2018
}

APPROVED BY:

Margaret M. Sugg, Ph.D.

Chairperson, Thesis Committee

Jennifer R. Runkle, Ph.D.

Member, Thesis Committee

Elizabeth D. Shay, Ph.D.

Member, Thesis Committee

Kara E. Dempsey, Ph.D.

Member, Thesis Committee

Kathleen Schroeder, Ph.D.

Chairperson, Department of Geography and Planning

Max C. Poole, Ph.D.

Dean, Cratis D. Williams School of Graduate Studies 
Copyright by Laura K. Thompson 2018

All Rights Reserved 


\title{
Abstract \\ ADOLESCENTS IN CRISIS: A GEOGRAPHIC EXPLORATION OF HELP-SEEKING BEHAVIOR USING DATA FROM CRISIS TEXT LINE
}

\author{
Laura K. Thompson \\ B.A., University of Tennessee \\ M.A., Appalachian State University
}

Chairperson: Margaret M. Sugg

Prior research has demonstrated that a variety of demographic, socioeconomic, and environmental factors can influence the prevalence and severity of mental distress and whether an individual is likely to receive treatment. Behavioral health research has been limited to self-reported survey data, but advances in technology have provided increased opportunities to continuously capture and store data, and to learn about the help-seeking habits of its contributors. In response to the growing prevalence of technologically mediated crisis counseling services, this county-level ecological study evaluated whether these same disparities exist for help-seeking via Crisis Text Line, a free, ubiquitous, technology-based crisis counseling service. Because most suicide attempts are impulsive acts, crisis hotlines are often the only resource available to suicidal or at-risk individuals. It is critical that researchers and practitioners are aware of any population-level disparities limiting the use of these invaluable resources. To date, this is the first study to examine text-based help-seeking behavior among adolescents at a national scale. Results identify several factors associated with increased or reduced help-seeking behavior among adolescents in the U.S. Increased 
rates of CTL usage occur in counties with higher mean household incomes, higher divorce rates, and lower residential stability. Rurality was the strongest predictor for low rates of help-seeking, and this finding is particularly concerning in light of elevated rates of suicide among rural counties. Low rates of help-seeking compound ongoing rural-urban disparities in traditional mental health services, and this finding suggests that increased suicide risk in rural areas cannot be explained by mental health professional shortages alone. Rural communities, particularly those with low support-seeking behavior and comparatively high suicide rates, should be the target of future research and outreach. 


\section{Acknowledgments}

I am indebted to numerous people for their ongoing support throughout my graduate career and the completion of my master's thesis at Appalachian State. First and foremost, I would like to thank my parents: Suzan and Bill Thompson. I was given countless opportunities throughout my childhood to explore my creativity and become a lifelong learner. I thank my mother for encouraging me to not shy away from opportunities that intimidate me, as they provide some of the greatest opportunities for personal growth. It is her voice I hear just before I submit an application or step in front of an audience to share my research. I thank my father for sharing his passion for mathematics and computers with me. Thanks also to my sisters Amy and Jenny for their inspiration and encouragement.

The highlight of my graduate education has been the opportunity to work with my advisor and thesis committee Chair, Dr. Maggie Sugg. Dr. Sugg has gone above and beyond the call of duty as my academic mentor. Her patience, kindness, and responsiveness has had a tremendous impact upon my experiences and success here at Appalachian. Dr. Sugg constantly provided feedback on my research and actively pursued additional academic and professional development opportunities for me. I would be hard pressed to find another advisor as invested in her student’s research and future success as Dr. Sugg. I thank her for her support these past two years and hope to continue to collaborate with her in the future.

Another professor I have been fortunate to work with is Dr. Elizabeth Shay. Dr. Shay has mentored me throughout an ongoing qualitative research project and is serving on my 
thesis committee. She has provided me opportunities for research and leadership positions as well as supported me throughout the development of my first oral conference presentation in the fall of 2017. I am grateful for her valuable feedback on my thesis and for her guidance throughout my time here at Appalachian.

Though Dr. Jennifer Runkle is not local to Boone, she has been immensely helpful on a variety of research projects, providing an invaluable public health and epidemiological perspective to my work. Dr. Runkle has provided substantial editing and modeling recommendations, and also co-authored the Crisis Text Line grant with Dr. Sugg that is the focus of this thesis. I am fortunate to have her on my thesis committee and to have worked on several projects with her. I thank her for her time and hope to continue to work with her in the future.

I also thank Dr. Kara Dempsey for serving on my thesis committee, and providing valuable political and contextual perspectives to my committee’s discussion. Dr. Sugg, Dr. Shay, and Dr. Dempsey provided me with my GRAM assistantship that has provided financial support and numerous research opportunities throughout my time at Appalachian. Many thanks to Dr. Kurt Michael for taking the time to review and discuss my preliminary results and offer your expertise as an adolescent psychologist and suicide prevention specialist.

Thank you to our capable program director, Dr. Baker Perry, who gave me the opportunity to serve as his graduate assistant last summer on his annual Peru trip. Dr. Perry provided financial support and the opportunity to see the "teaching side" of graduate school for a short time. It was my first trip abroad, and I am grateful for the opportunity provided to grow my leadership skills on such an amazing trip. 
I would not have made it through the challenges of moving across the country and starting a graduate program without the friendship of my fellow graduate students. Whether it is providing academic support or company during a well-earned break, I will cherish the friendships I have made in this program. I cannot thank my closest friend, David Vines, enough for his support these past two years. I am grateful for all the running, camping, and climbing I have done with David, Heather Guy, Evan Montpellier, Zeb Sanders and Burke McDade. I thank my friend and desk partner Lauren Andersen for setting the bar high with her work ethic and organization, and for her companionship in Peru and at various conferences. I take it as a compliment when anyone accidently calls me Lauren. I also thank Abie Bonevac for her friendship and her work on our collaborative projects. Know that whether you have been mentioned by name or not, I am grateful for your support, friendship, and collaboration.

Finally, I would like to thank Crisis Text Line for sharing their data with me. This data is, to my knowledge, the first of its kind, and Crisis Text Line should be recognized for realizing the unique opportunity these data provide behavioral health researchers, and for taking the steps to responsibly and securely share them with others in the field. 


\section{Table of Contents}

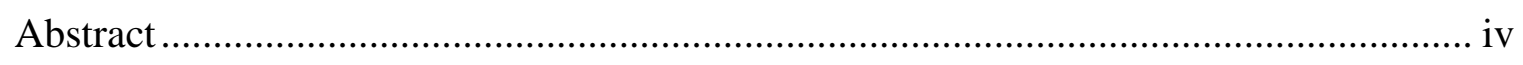

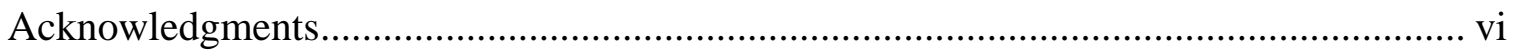

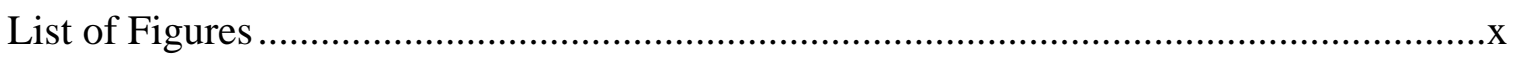

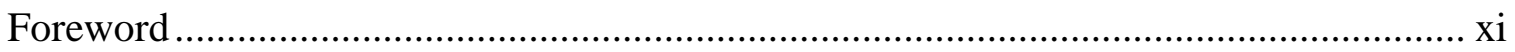

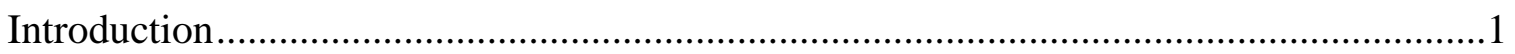

Journal Article: Adolescents in Crisis: A Geographic Exploration of Help-Seeking

Behavior Using Data from Crisis Text Line ..............................................................4

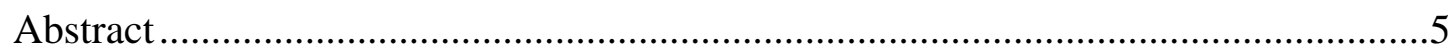

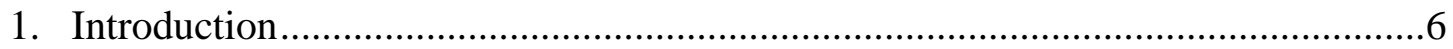

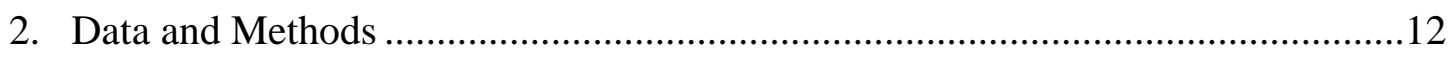

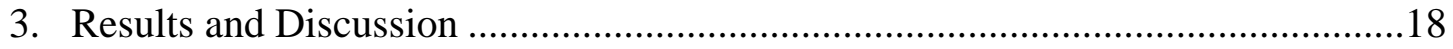

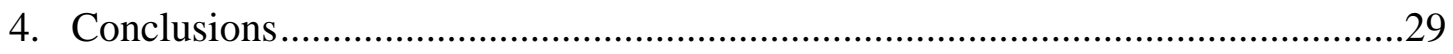

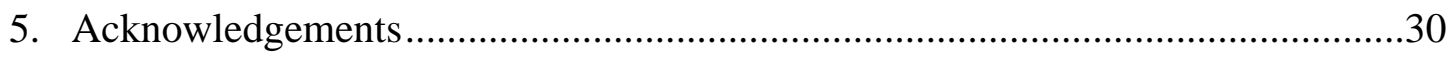

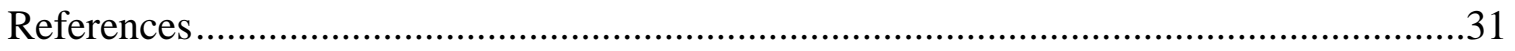

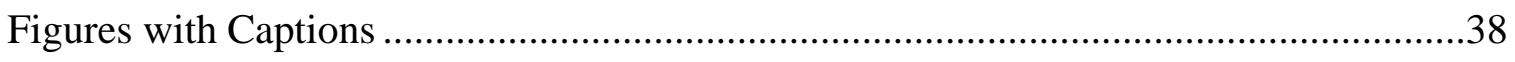

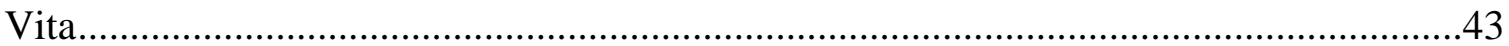




\section{List of Figures}

Figure 1. CTL conversation annual rate by county, grouped by U.S. Census division. The Northeast region was not split by division (quantile breaks) .38

Figure 2. Boxplot of annual suicide rate compared to help-seeking for suicidal thoughts by

RUCC

This list is required ONLY if you will NOT be placing the figures in the text near where they are referenced OR if your style requires it.

Figure 3. Ratio of annual rate of suicide to annual rate of help-seeking for suicidal thoughts

Figure 4. Percent Change in CTL annual conversation rate between August 2013 and July 2017 (Quantile Breaks)

Figure 5. Boxplot of annual suicide rate for the total population and the under 35 population, compared to help-seeking for suicidal thoughts by RUCC. Because this age-based subset of the population results in a suppression of rates for an additional 880 counties with low counts of suicide, and because 489 of these additional suppressed rates are from counties with RUCCs 8 and 9, suicide rates for the total population were used, and this figure is supplied for reference only 


\section{Foreword}

The main body of this thesis is formatted according to the guidelines for manuscript submission to Social Science and Medicine, an international peer-reviewed journal published by Elsevier. 


\section{Introduction}

Prior research has shown that less than half of adolescents with a mental disorder receive any type of treatment (Burns et al., 1995; Costello et al., 2014). Adolescents are particularly vulnerable to mental distress-approximately one-half of chronic mental health disorders begin by the age of fourteen, and three-quarters begin by the age of twenty-four (Kessler et al., 2005). Populations with a history of being underserved (i.e., those with lower socioeconomic status, racial and ethnic minorities, and individuals living in rural areas) experience elevated risk for mental distress and are less likely to receive treatment or engage in help-seeking behavior (Barkan et al., 2013; Reiss, 2013; Fontanella et al., 2015; VanderWielen et al., 2015; Center for Behavioral Health Statistics and Quality, 2016; Nestor et al., 2016).

As technology has become more and more integrated with our daily lives, mental health services have expanded to include these new platforms. Crisis hotlines were developed to provide immediate support during the acute periods of crisis commonly associated with mental disorders and suicidality (Mishara and Daigle, 2000). Crisis hotlines have demonstrated effectiveness at reducing crisis severity, feelings of hopelessness, and suicidality (Kalafat et al., 2007; Gould et al., 2007). These services are characterized by free, immediate, and anonymous counseling. Research on survivors of suicide attempts found most suicide attempts are made within 10 minutes of initial suicidal ideation (Deisenhammer et al., 2009), a statistic that highlights the critical role a crisis hotline can play in suicide prevention. It is critical that researchers and practitioners are aware of any population-level disparities limiting the use of these resources. Recently, remote crisis counseling services have expanded into new platforms with the development of online and text-based resources 
that are more widely used by adolescent populations (Evans et al., 2013). Because these services are so new, little is known about the underlying patterns of use, and whether or not traditional disparities in help-seeking and mental health treatment persist across these platforms.

The power these new technologies hold for researchers is their ability to help answer these questions through the passive collection of behavioral health data. Often, these data are geo-referenced, making them a powerful resource for understanding the spatial distribution of adolescent help-seeking. This study uses geo-referenced data from a ubiquitous, technology-based crisis counseling service to explore help-seeking behavior in the U.S. at the county level. To the authors' knowledge, this is the first study to examine text-based helpseeking behavior among adolescents at a national scale. Data is available through Crisis Text Line (CTL), a free crisis counseling service launched in 2013 in response to the growing popularity of text-message based communication among adolescents. CTL is widely used across the U.S., and volunteer counselors have engaged in over 800,000 conversations since its inception. Detailed records of each CTL conversation provide novel insight into adolescent and young adult help-seeking behavior.

This ecological study uses correlation, spatial error multiple regression models, and group difference analysis to explore demographic, socioeconomic, and environmental factors that predict text-based help-seeking behavior among adolescents in the U.S. Health surveillance data is expected to grow in popularity, and this study lays a foundation in anticipation for a growing body of work using these data to study behavioral health at both population and individual scales. Understanding the role technology mediated services play in crisis support can help researchers and crisis organizations target locations and populations 
that underuse mental health services. Ultimately, this study aims to highlight persistent disparities in mental health treatment that can be addressed by policy-makers and practitioners with the intent to improve crisis support and reduce mental distress for all adolescents. 


\title{
ADOLESCENTS IN CRISIS: A GEOGRAPHIC EXPLORATION OF HELP- SEEKING BEHAVIOR USING DATA FROM CRISIS TEXT LINE
}

\author{
Laura K. Thompson $^{\mathrm{a}}$, Margaret M. Sugg ${ }^{\mathrm{b}}$, Jennifer R. Runkle
}

aDepartment of Geography and Planning, Appalachian State University, P.O. Box 32066, Boone, North Carolina 28608, United States of America, thompsonlk1@appstate.edu, (865) 386-6622 (Corresponding author)

bDepartment of Geography and Planning, Appalachian State University, P.O. Box 32066, Boone, North Carolina 28608, United States of America, kovachmm@appstate.edu

${ }^{\mathrm{c}}$ North Carolina Institute for Climate Studies, North Carolina State University, 151 Patton Avenue, Asheville, NC 28801, United States of America, jrrunkle@ncsu.edu 


\begin{abstract}
Prior research has demonstrated that a variety of demographic, socioeconomic, and environmental factors can influence the prevalence and severity of mental distress and the likelihood of an individual receiving treatment. Behavioral health research has been limited to self-reported survey data, but advances in technology have provided increased opportunities to continuously capture and store data, and to study the help-seeking habits of its contributors. In response to the growing prevalence of technologically mediated crisis counseling services, this county-level ecological study evaluated whether these same disparities exist for help-seeking via Crisis Text Line, a free, ubiquitous, technology-based crisis counseling service. Because most suicide attempts are impulsive acts, crisis hotlines are often the only resource available to suicidal or at-risk individuals. It is critical that researchers and practitioners are aware of any population-level disparities limiting the use of these invaluable resources. To date, this is the first study to examine text-based help-seeking behavior among adolescents at a national scale. Results identify several factors associated with increased or reduced help-seeking behavior among adolescents in the U.S. Increased rates of CTL usage occur in counties with higher mean household incomes, higher divorce rates, and lower residential stability. Rurality was the strongest predictor for low rates of help-seeking, and this finding is particularly concerning in light of elevated rates of suicide among rural counties. Low rates of help-seeking compound ongoing rural-urban disparities in traditional mental health services, and this finding suggests that increased suicide risk in rural areas cannot be explained by mental health professional shortages alone. Rural communities, particularly those with low support-seeking behavior and comparatively high suicide rates, should be the target of future research and outreach.
\end{abstract}




\section{Keywords}

Adolescent Mental Health, help-seeking, crisis hotline, United States

\section{Introduction}

The World Health Organization estimates one in every four to five individuals worldwide will develop a mental disorder during their lifetime (World Health Organization, 2001). Adolescents are particularly vulnerable to mental distress-approximately one-half of chronic mental health disorders begin by the age of fourteen, and three-quarters begin by the age of twenty four (Kessler et al., 2005). However, studies have shown that less than half of adolescents with a mental disorder receive any type of treatment (Burns et al., 1995; Costello et al., 2014), and these rates are higher for populations with a history of being underserved, including those with lower socioeconomic status, racial and ethnic minorities, and individuals living in rural areas (Wang et al., 2016).

Crisis hotlines were developed in recognition of the occurrence of acute periods of crisis associated with mental disorders and suicidality (Mishara and Daigle, 2000). Research on survivors of suicide attempts found most suicide attempts are made within 10 minutes of initial suicidal ideation (Deisenhammer et al., 2009). Crisis hotlines and other technologically mediated mental health resources provide a unique and critical service that is available continuously, anonymously, and at no cost. Crisis hotlines have demonstrated effectiveness at reducing crisis severity, feelings of hopelessness, and suicidality (Kalafat et al., 2007;

Gould et al., 2007). 
In August of 2013, Crisis Text Line (CTL) was established in response to the growing popularity of text-message based communication among adolescents. This free crisis counseling service is widely used across the U.S., and volunteer counselors have engaged in over 800,000 conversations since its inception. Adolescents have reported a preference for text-based communication over traditional call-based hotlines (Evans et al., 2013), suggesting text-message hotlines may reach new populations. Detailed records of each CTL conversation provide novel insight into adolescent and young adult help-seeking behavior. CTL, search engines, and other technology platforms passively collect data that can provide valuable insight into mental health at spatial and temporal scales unprecedented by traditional standards.

Prior research has demonstrated that a variety of demographic, socioeconomic, and environmental factors can influence the prevalence and severity of mental distress and whether an individual is likely to receive treatment (Barkan et al., 2013; Reiss, 2013; Fontanella et al., 2015; VanderWielen et al., 2015; Center for Behavioral Health Statistics and Quality, 2016; Nestor et al., 2016). The present study seeks to evaluate whether these same disparities exist for a ubiquitous, technology-based crisis counseling service. To the authors' knowledge, this is the first study to examine text-based help-seeking behavior among adolescents at a national scale. Using data from CTL, this ecological study seeks to evaluate, the underlying demographic, socioeconomic, and environmental factors that are associated with increased or reduced help-seeking behavior among adolescents in the U.S. Understanding the role these new services play in crisis support can help researchers and crisis organizations target populations that underuse mental health services and, ultimately, work towards improving crisis support services for all adolescents. 


\subsection{Socioeconomic status}

Lower socioeconomic status has been linked to increased occurrence of mental health issues (Spady et al., 2001; Amone-P’Olak et al., 2009; Reiss, 2013). In a systematic review of studies examining socioeconomic status, Reiss determined that youth with low socioeconomic status were between two and three times more likely to develop a mental health issue (2013). Low socioeconomic status also reduces the likelihood that an individual will receive any form of mental health treatment (Center for Behavioral Health Statistics and Quality, 2016). A recent national survey found adolescents in poverty were less likely to receive both specialized and non-specialized mental health services, including treatment through family medicine and educational institutions (Center for Behavioral Health Statistics and Quality, 2016). Results of this survey suggest even relatively affordable or no cost mental health services are utilized less by individuals in poverty.

\subsection{Race and Ethnicity}

Mental health outcomes related to race and ethnicity in the U.S. have strong ties to socioeconomic status (Alegria et al., 2015). There are more than twice as many black and Hispanic adolescents living in poverty (34\% and 28\%, respectively) than non-Latino white adolescents (12\%) (Kids Count Data Center, 2017). Thus, much of the disparity in mental health outcomes across racial and ethnic groups can be explained by socioeconomic status and other neighborhood-level factors such as segregation, social isolation, and exposure to violent crime (Williams and Earl, 2007, Alegria et al., 2015). Further, research on mental health service has shown mental health services are less available in neighborhoods with higher racial and ethnic minority populations, making it more challenging for minority 
populations to receive treatment (VanderWielen et al., 2015). Stigma and mental health education may also play a role in racial and ethnic disparities in treatment (Batterham et al., 2013).

\subsection{Population Density, Rurality, and Isolation}

Despite a history of conflicting results regarding the prevalence of mental health issues among rural versus urban populations (Probst et al., 2006; Peen et al., 2010; Galea et al., 2011), recent research found no significant relationship (Smith et al., 2008; Breslau et al., 2014). There are, however, well-established disparities in access to mental health treatment among rural populations. More than 85 percent of federally designated mental health professional shortage areas (HPSAs) are located in rural areas (Bird et al., 2001). Of the more than 3,000 Rural Health Centers in the U.S., less than four percent have a doctoral-level psychologist or clinical social worker on staff (National Advisory Committee on Rural Health and Human Services, 2010).

One of the most critical mental health issues disproportionately affecting rural areas is suicide. Suicide rates in the most rural locations are nearly double those found in the most urban locations, and this gap is widening and found among adolescents (Fontanella et al., 2015). Several possible explanations for this have been proposed, including a lack of mental health services in rural locations, cultural factors (e.g., stigma), social isolation, access to lethal means, and socioeconomic factors (Fontanella et al., 2015). 


\subsection{Other Population Characteristics}

Prior research has identified several other sociodemographic characteristics that may have a relationship with mental health outcomes and treatment. Lower educational attainment results in lower suicide literacy (Batterham et al., 2013), and adolescents with less educated parents experienced increased severity and persistence of Diagnostic and Statistical Manual of Mental Disorders (DSM-IV) disorders (McLaughlin et al., 2011). Interestingly, parental education seems to have a different relationship to mental health outcomes than income levels (McLaughlin et al., 2011; Alegria et al., 2015), suggesting that the benefits of education on mental health outcomes relates to more than just economics.

Divorce has one of the most consistent relationships with mental health. In studies of adults, a significant relationship has been found between divorce and depression (AkhtarDanesh and Landeen, 2007) and suicide (Hempstead, 2006). Less research has been done on the impact of parental divorce on adolescent mental health, but Merikangas et al. found adolescents with divorced parents were more likely to use mental health services than those with married or cohabiting parents (2011).

One of the most well established theories on suicide is Durkheim's theory of social integration ([1897] 1951), which suggests that clusters of suicide occur in areas with weak social ties resulting from high population turnover (Baller and Richardson, 2016). Residential stability is often measured using the portion of the population that has recently moved and the portion of housing that is renter-occupied housing (Cutchin and Churchill, 1999; Messer et al., 2006; Barkan et al., 2013). In an attempt to explain the east-to-west divide in suicide rates, one study found an association between residential instability and suicide rate (Barkan et al., 2013). 


\subsection{Help-seeking via New Media}

Crisis and suicide prevention hotlines acknowledge the need for easily accessible support for acute mental distress or suicidal ideation (Mishara and Daigle, 2000). Recently, remote-access counseling services have expanded into new platforms with the development of online and text-based resources. Telephone and other remote counseling services offer several benefits to users, the most obvious being the accessibility of these services and the immediacy with which individuals can receive counseling (Lester and Rogers, 2012). Clients also have more control over when they receive help, can end the session at any time, and are able to remain anonymous (Lester and Rogers, 2012). This increased sense of control and privacy can make the difference in whether or not an individual will seek help during a crisis, particularly for individuals who feel stigmatized (Lester and Rogers, 2012). As a result, remote crisis counseling may encourage help-seeking among populations that have been traditionally less likely to receive support for mental distress (Lester and Rogers, 2012; Evans et al., 2013; Haner and Pepler, 2016).

These new crisis services also benefit researchers. Because these data are collected continuously and are not mediated by researchers, they are less likely to be affected by memory bias and experimenter demand effects (De Choudhury et al., 2013). These data are also one of the few sources of behavioral health data available in near real-time (Ayers et al., 2014). Several studies have demonstrated the ability of these high-resolution data to monitor and quickly detect trends in mental distress and suicidal ideation (Sueki, 2011; Yang et al., 2011; Ayers et al., 2013; Gunn and Lester, 2013; Jashinsky et al., 2014; Ayers et al., 2016). For example, in a state-level analysis Gunn and Lester identified positive associations between internet searches for suicide-related terms and a state’s suicide rate (2013). 


\subsection{Objectives}

Technologically mediated crisis support holds great potential for users, researchers, and practitioners, but because these services are relatively new, little research has studied the factors that influence the use of these services. Because of the aforementioned disparities in mental health outcomes, treatment, and help-seeking in the U.S., understanding whether these new services perpetuate or reduce these disparities is critical towards improving these services and developing more inclusive public mental health strategies. CTL provides a novel platform for counseling and crisis support. To the author's knowledge, this study is the first to measure help-seeking behavior for a text-based crisis support service at a national scale. The aim of this ecological study is to identify socioeconomic, demographic, and environmental conditions associated with increased or decreased text-based help-seeking behavior. To explore these relationships, the following research questions were investigated:

1) What predictors (socioeconomic, demographic, environmental) influence help-seeking behavior for depression, anxiety, and suicidal thoughts among adolescents in the U.S.?

2) What are the trends in text-based help-seeking behavior between adolescents across the rural-urban continuum?

\section{Data and Methods}

\subsection{Crisis Text Line Data}

CTL conversation records were available from August 2013 through July 2017 (n = 849,483). CTL filtered these data to remove prank messages and those in which the texter did not engage in conversation after initial contact. Each conversation was associated with a 
county based on the first six digits of the user’s phone number (NPANXX). Data were aggregated to yearly temporal resolution and county spatial resolution for analysis to protect user privacy. Based on an optional survey administered at the end of a counseling session, approximately 95.6 percent of individuals using CTL are under the age of $35(n=63,779$ of 66,690 conversations reporting age). Because CTL is predominantly used by adolescents and young adults, annual rates of CTL usage were calculated using a subset of each county's population (under age 35) available from the U.S. Census 2010 population estimates (U.S. Census, 2010).

Preliminary descriptive statistics identified a number of counties with extreme annual rates likely to limit the ability to create a predictive model for the majority of data. The most severe outliers were systematically removed from the data by trimming the top and bottom one percent of county CTL conversation rates. Because the bottom one percent of the data was made up of counties with no data, a random number generator was used to randomize removal. This reduced the sample size from 3,143 to 3,080 counties and county equivalents. Known as trimming the mean, this approach has been used frequently to more accurately reflect the relationships found for the vast majority of the data, while minimizing the amount of data lost (Erceg-Hurn and Mirosevich, 2008).

Following each conversation, CTL counselors assign one or more issues discussed to the conversation based on an established list of crisis concerns $(n=28)$. Table 1 provides a list of the eight issues that occur in more than 10 percent of conversations. Analysis was performed using total conversion rates as well as conversation rates for anxiety, depression, and suicidal thoughts specifically. Anxiety, depression, and suicidal thoughts were selected because they are well-known and pervasive mental health concerns. Further, they appear in a 
large percentage of conversations and allow for greater spatial resolution. The suicidal thoughts tag was preferable to the suicidal desire tag, because the latter tag was not established until 2015. Despite their prevalence, the family and relationship tags were not the focus of this study, because they refer to causes, not outcomes, of mental distress. The Appalachian State University Institutional Review Board determined this study was exempt from human subjects review.

Table 1. CTL issues tagged in over 10 percent of all conversations.

\begin{tabular}{|c|c|c|c|c|c|}
\hline Rank & Issue & Frequency* & Rank & Issue & Frequency* \\
\hline 1 & Depressed & $27.9 \%(n=236964)$ & 5 & Relationship & $17.3 \%(\mathrm{n}=146751)$ \\
\hline 2 & Suicidal Thoughts & $21.1 \%(\mathrm{n}=179118)$ & 6 & Stress & $16.6 \%(n=141145)$ \\
\hline 3 & Family & $19.4 \%(n=165211)$ & 7 & Suicidal Desire & $16.5 \%(n=140320)$ \\
\hline 4 & Anxiety & $17.6 \%(n=149251)$ & 8 & Self Harm & $11.5 \%(n=97316)$ \\
\hline
\end{tabular}

*Multiple issues may be tagged in a single conversation.

\subsection{County-level Explanatory Variables}

Fifteen potential explanatory variables, listed in Table 2, were identified based on a review of prior research exploring determinants of mental health outcomes and help-seeking. Data for most variables was available through the American Community Survey (ACS) 5year-estimates (U.S. Census, 2015). Socioeconomic variables included mean household income, poverty, unemployment, and low educational attainment (Spady et al., 2001; Amone-P'Olak et al., 2009; Reiss, 2013; Center for Behavioral Health Statistics and Quality, 2016). Demographic variables included race, ethnicity, divorce, single parent homes, population density, and Rural-Urban Continuum Codes (RUCC) (Sen, 2004; Hempstead, 2006; Akhtar-Danesh and Landeen, 2007; Alegria et al., 2015; Fontanella et al., 2015; VanderWielen, et al. 2015; Nestor et al., 2016). Residential stability was measured using 
renter-occupied homes and individuals living in a different home during the past twelve months (Cutchin and Churchill, 1999; Barkan et al., 2013).

Table 2. Mental Health and Help-Seeking Determinants, 3,220 counties and county equivalents

\begin{tabular}{|c|c|c|}
\hline Category & Data Source & Variable Definition \\
\hline \multirow[t]{4}{*}{ Socioeconomic } & ACS (2015, 5-year Est.) & Mean Household Income (dollars) \\
\hline & ACS (2015, 5-year Est.) & $\begin{array}{l}\text { Percent population below poverty level in the past } 12 \\
\text { months }\end{array}$ \\
\hline & ACS (2015, 5-year Est.) & Percent population unemployed (16 years and over) \\
\hline & ACS (2015, 5-year Est.) & $\begin{array}{l}\text { Percent population less than high school graduate ( } 25 \\
\text { years and over) }\end{array}$ \\
\hline \multirow[t]{6}{*}{ Demographic } & ACS (2015, 5-year Est.) & Percent population minority \\
\hline & ACS (2015, 5-year Est.) & Percent population Hispanic or Latino \\
\hline & ACS (2015, 5-year Est.) & Percent population divorced (15 years and over) \\
\hline & ACS (2015, 5-year Est.) & Percent households with single parent \\
\hline & ACS (2015, 5-year Est.) & Population Density (Land area (Mi. Sq) / Total population) \\
\hline & $\begin{array}{l}\text { U.S. Department of } \\
\text { Agriculture (2013) }\end{array}$ & Rural-Urban Continuum Codes \\
\hline \multirow[t]{2}{*}{$\begin{array}{l}\text { Residential } \\
\text { Stability }\end{array}$} & ACS (2015, 5-year Est.) & $\begin{array}{l}\text { Percent families living in a different residence during the } \\
\text { past } 12 \text { months }\end{array}$ \\
\hline & ACS (2015, 5-year Est.) & Percent home renter-occupied \\
\hline \multirow[t]{2}{*}{ Climate } & U.S. Census (2016) & Latitude of county centroids (TIGER/Line Shapefile) \\
\hline & $\begin{array}{l}\text { National Renewable Energy } \\
\text { Laboratory (2009) }\end{array}$ & $\begin{array}{l}\text { Mean annual Global Horizontal Irradiance } \\
\left(\mathrm{kWh} / \mathrm{m}^{2} / \text { day }\right)^{\mathrm{a}}\end{array}$ \\
\hline \multirow[t]{2}{*}{ Mental Health } & $\begin{array}{l}\text { Health Professional } \\
\text { Shortage Areas (HPSA } \\
\text { 2017) }\end{array}$ & Average Mental Health Professional Shortage Score (0-25) \\
\hline & $\begin{array}{l}\text { Centers for Disease Control } \\
\text { (2016) }\end{array}$ & Raw annual suicide rate, $1999-2016$ \\
\hline
\end{tabular}

Data for 48 contiguous U.S. states.

Latitude and mean annual global horizontal irradiance (GHI, $\mathrm{kWh} / \mathrm{m}^{2} /$ day) were used to explore the influence of climate and sunlight on help-seeking behavior for mental distress. Latitude was calculated using the centroid of each county polygon in the 2016 TIGER/Line county shapefile (U.S. Census Bureau, 2017). Mean annual GHI was available for the 
contiguous U.S. and was averaged using data from 1998 to 2009 (National Renewable Energy Laboratory, 2012).

Annual suicide rate, averaged from 1999 to 2016 was available through the Centers for Disease Control (CDC) (CDC, 2016a). This temporal period was selected to minimize the number of counties for which suicide was suppressed by the CDC. The CDC suppresses suicide rate for any county with fewer than ten suicides during the selected time frame ( $\mathrm{n}=$ 225) (CDC, 2016a), and is biased towards counties with low populations. The CDC considers any death count below twenty to be unreliable, but to maximize representation from rural counties, these data were retained. Data on Mental HPSAs areas were available through the Health Resources and Services Administration, which assigns scores to each mental health service area based on degree of unmet need (Health Resources and Services Administration, 2018).

\subsection{Methods}

\subsubsection{Regional Covariates}

To investigate the relationship between demographic, socioeconomic, and environmental conditions and CTL use, effect sizes and associated p-values were calculated with Spearman's rank correlation using the psych package in R version 3.3.1 (R Core Team, 2016; RStudio Team, 2016; Revelle, 2017). To explore regional differences in relationships, correlations were run for each census division with the exception of the Northeast, which was aggregated to the regional level to more closely approximate spatial coverage and county sample sizes of other divisions. The map in Figure 1 shows each county’s annual conversation rate. 


\subsubsection{Spatial Error Regression}

Due to a large number of potential explanatory variables, a multivariate analysis using stepwise regression was applied to CTL use for depression, anxiety and suicide. Due to the non-normal nature of CTL data, a log transform was used to reduce the right-skewness and was incorporated as the dependent variable in the stepwise and spatial error regression analysis. Stepwise regression using both forward and backward directions identified eight variables for inclusion in a final regression model: Divorce, rental homes, aggregate RUCC groups ( $\mathrm{n}=5$ categories), mean household income, Hispanic, minority, low educational attainment, and single parent homes. Multicollinearity between the remaining variables was evaluated using the variance inflation factor (VIF). The VIF for single parent homes was the highest (VIF = 4.1), and all other variables were below 3.2, indicating no significant multicollinearity. An ordinary least squares multiple linear regression model (OLS) residuals were tested for spatial autocorrelation using Moran’s I (Kovach et al., 2015), indicating spatial autocorrelation (p-value $<0.01$ ). Spatially autocorrelated residuals violate the assumptions of OLS models. The Lagrange multiplier test for spatial dependence identified spatial error as the preferred model for the data through the calculation of the Robust Lagrange Multiple Index (p-value $<0.01$ ). In the spatial error regression model, the spatial error term incorporates spatial dependence using a spatial weight matrix. The spatial weights

matrix used for the model was specified using first order queens case, which is insensitive to varying county sizes. Eight island counties with no neighbors were removed $(\mathrm{n}=3,072)$. The residuals of the spatial error regression measured no significant spatial autocorrelation (Moran's I $=-0.22$, p-value $=0.82$ ), indicating the model successfully incorporated the spatial effects. 


\subsubsection{Rural-Urban differences in help-seeking}

To further examine rural-urban differences in help-seeking, the Dunnett-TukeyKramer (DTK) Pairwise Multiple Comparison Test was run using the DTK package to account for unequal sample sizes and unequal variances among groups (Lau, 2013). Counties were assigned to five groups based on RUCC, as shown in Table 3. Group mean differences were calculated between the annual rate of help-seeking for suicidal thoughts and suicide rates $(\alpha=0.01)$.

Table 3. Rural-urban groups

\begin{tabular}{llll}
\hline Category & RUCC & Description & Count* $^{*}$ \\
\hline Large Metro & 1 & Counties in metro areas of 1 million population or more & 421 \\
Small Metro & 2,3 & Counties in metro areas of few than 1 million population & 729 \\
Non-Metro & 4,5 & Non-metro urban population of 20,000 or more & 304 \\
Semi-Rural & 6,7 & Non-metro urban population of 2,500 to 19,999 & 1013 \\
Rural & 8,9 & Completely rural or less than 2,500 urban population & 613 \\
\hline
\end{tabular}

*Count represents data with trimmed means (3,080 counties)

\section{Results and Discussion}

\subsection{Covariates of CTL help-seeking}

Table 4 lists Spearman correlation coefficients for the U.S. and each census division. Coefficients were calculated for conversation rate (any issue), as well as anxiety, depression, and suicidal thoughts. Correlation coefficients for anxiety, depression, and suicidal thoughts are, in general, well-represented by coefficients for all conversations. This consistency is due in part to the large proportion of conversations containing these issues, and in part because anxiety, depression, and suicidal thoughts are highly correlated (Anxiety-Depression $\rho=$ 0.85***, Anxiety-Suicide $\rho=0.79^{* * *}$, Depression-Suicide $\rho=0.87^{* * *}$ ). 
Table 4. Spearman Correlation Coefficients for each census division. Coefficients are reported for any conversation and conversations tagged with anxiety, depression, and suicidal thoughts.

\begin{tabular}{|c|c|c|c|c|c|c|c|c|c|}
\hline Variable & $\begin{array}{l}\text { US Total }^{\mathbf{a}} \\
(\mathrm{n}=3,080)\end{array}$ & $\begin{array}{c}\text { Pacific } \\
(\mathrm{n}=166)\end{array}$ & $\begin{array}{c}\text { Mountain } \\
(\mathrm{n}=274)\end{array}$ & $\begin{array}{c}\text { W. } \\
\text { North } \\
\text { Central } \\
(\mathrm{n}=598)\end{array}$ & $\begin{array}{c}\text { E. North } \\
\text { Central } \\
(\mathrm{n}=431)\end{array}$ & $\begin{array}{c}\text { W. } \\
\text { South } \\
\text { Central } \\
(\mathrm{n}=463)\end{array}$ & $\begin{array}{c}\text { E. South } \\
\text { Central } \\
(n=364)\end{array}$ & $\begin{array}{c}\text { South } \\
\text { Atlantic } \\
(\mathrm{n}=568)\end{array}$ & $\begin{array}{c}\text { Northeast } \\
(\mathrm{n}=216)\end{array}$ \\
\hline $\begin{array}{l}\text { Household } \\
\text { Mean Income }\end{array}$ & $0.14 * * *$ & 0.11 & $0.26 * * *$ & $0.12 *$ & 0.06 & -0.06 & 0.13* & $0.11^{* *}$ & 0.09 \\
\hline Anxiety & $0.20 * * *$ & $0.23 * *$ & $0.18^{* *}$ & $0.18^{* * *}$ & $0.11^{*}$ & 0.06 & $0.19 * * *$ & $0.17 * * *$ & $0.17 *$ \\
\hline Depression & $0.17 * * *$ & 0.12 & $0.28 * * *$ & $0.14^{* * *}$ & 0.08 & 0.01 & $0.15^{* *}$ & $0.14 * * *$ & 0.09 \\
\hline Suicidal & $0.17^{* * *}$ & -0.01 & $0.27 * * *$ & $0.16^{* * *}$ & $0.10^{*}$ & 0.02 & $0.16^{* *}$ & $0.14^{* * *}$ & 0.04 \\
\hline Poverty & 0.01 & -0.07 & -0.04 & $0.09 *$ & $0.16 * * *$ & 0.10* & -0.03 & -0.01 & 0.09 \\
\hline Anxiety & -0.01 & -0.10 & -0.03 & $0.11 *$ & $0.14^{* *}$ & 0.08 & -0.08 & -0.04 & 0.03 \\
\hline Depression & 0.00 & -0.03 & -0.04 & $0.10^{*}$ & $0.15^{* *}$ & 0.08 & -0.07 & -0.02 & 0.10 \\
\hline Suicidal & 0.00 & 0.07 & -0.07 & $0.09 *$ & $0.16^{* *}$ & 0.06 & -0.06 & -0.02 & 0.11 \\
\hline Unemployment & $0.09 * * *$ & -0.05 & 0.10 & $0.21 * * *$ & 0.09 & 0.09 & $-0.18 * * *$ & 0.01 & -0.01 \\
\hline Anxiety & $0.09 * * *$ & -0.13 & $0.15^{*}$ & $0.23^{* * *}$ & 0.08 & 0.07 & $-0.19 * * *$ & 0.02 & -0.04 \\
\hline Depression & $0.09 * * *$ & -0.02 & $0.16^{* *}$ & $0.22^{* * *}$ & 0.09 & 0.06 & $-0.17 * * *$ & 0.01 & 0.02 \\
\hline Suicidal & $0.09 * * *$ & -0.08 & $0.13^{*}$ & $0.24^{* * *}$ & 0.08 & 0.06 & $-0.13^{*}$ & 0.03 & -0.03 \\
\hline Low Education & $-0.14 * * *$ & $-0.22 * *$ & -0.09 & -0.05 & -0.07 & $-0.13^{* *}$ & $-0.11 *$ & $-0.20 * * *$ & -0.13 \\
\hline Anxiety & $-0.16^{* * *}$ & $-0.15^{*}$ & -0.04 & -0.05 & $-0.11^{*}$ & $-0.18 * * *$ & $-0.17^{* *}$ & $-0.25 * * *$ & $-0.15^{*}$ \\
\hline Depression & $-0.14 * * *$ & $-0.17^{*}$ & -0.07 & -0.06 & -0.07 & $-0.13^{* *}$ & $-0.12^{*}$ & $-0.20 * * *$ & -0.12 \\
\hline Suicidal & $-0.15^{* * *}$ & -0.12 & -0.05 & -0.07 & -0.08 & $-0.15^{* *}$ & $-0.15^{* *}$ & $-0.21^{* * *}$ & $-0.14^{*}$ \\
\hline Minority & 0.03 & -0.01 & 0.10 & $0.19 * * *$ & $0.28 * * *$ & $0.09 *$ & $-0.14^{* *}$ & -0.04 & 0.13* \\
\hline Anxiety & $0.05^{* *}$ & -0.01 & 0.06 & $0.24 * * *$ & $0.32 * * *$ & $0.10^{*}$ & -0.10 & -0.06 & $0.18^{* *}$ \\
\hline Depression & $0.05^{* *}$ & -0.04 & $0.16 *$ & $0.20^{* * *}$ & $0.30^{* * *}$ & 0.09 & $-0.15^{* *}$ & -0.01 & $0.16^{*}$ \\
\hline Suicidal & $0.05^{*}$ & -0.09 & $0.13 *$ & $0.22^{* * *}$ & $0.30^{* * *}$ & 0.05 & -0.09 & -0.02 & 0.08 \\
\hline Hispanic & $0.09 * * *$ & -0.05 & 0.11 & $0.19 * * *$ & $0.18 * * *$ & -0.07 & $0.23 * * *$ & $0.15^{* * *}$ & 0.07 \\
\hline Anxiety & $0.10^{* * *}$ & 0.11 & $0.15^{*}$ & $0.17 * * *$ & $0.21 * * *$ & -0.05 & $0.22 * * *$ & $0.18^{* * *}$ & 0.12 \\
\hline Depression & $0.09 * * *$ & 0.03 & $0.16^{*}$ & $0.16^{* * *}$ & 0.20 *** & -0.05 & $0.21 * * *$ & $0.16^{* * *}$ & 0.09 \\
\hline Suicidal & $0.11^{* * *}$ & 0.07 & $0.13^{*}$ & $0.19 * * *$ & $0.20^{* * *}$ & 0.00 & $0.22 * * *$ & $0.15^{* * *}$ & 0.01 \\
\hline Divorced & $0.17 * * *$ & $0.22 * *$ & $0.20 * * *$ & $0.21 * * *$ & $0.13^{* *}$ & $0.23^{* * *}$ & $0.22 * * *$ & $0.09 *$ & 0.09 \\
\hline Anxiety & $0.13^{* * *}$ & 0.15 & $0.18^{* *}$ & $0.19 * * *$ & 0.09 & $0.16^{* * *}$ & $0.17 * *$ & $0.08^{*}$ & 0.06 \\
\hline Depression & $0.14^{* * *}$ & $0.19 *$ & $0.18^{* *}$ & $0.17 * * *$ & 0.08 & $0.18^{* * *}$ & $0.18^{* * *}$ & 0.07 & 0.06 \\
\hline Suicidal & $0.15^{* * *}$ & $0.16^{*}$ & $0.19^{* *}$ & $0.20 * * *$ & 0.09 & $0.22 * * *$ & $0.15^{* *}$ & 0.05 & 0.12 \\
\hline $\begin{array}{l}\text { Single Parent } \\
\text { Household }\end{array}$ & $0.05^{* *}$ & -0.11 & $0.14 *$ & $0.20 * * *$ & $0.22 * * *$ & 0.11* & -0.08 & -0.04 & $0.19 * *$ \\
\hline Anxiety & $0.06 * * *$ & -0.08 & $0.18^{* *}$ & $0.24 * * *$ & $0.20 * * *$ & $0.10^{*}$ & -0.08 & -0.06 & $0.19 * *$ \\
\hline Depression & $0.06^{* * *}$ & -0.07 & $0.18^{* *}$ & $0.20^{* * *}$ & $0.21^{* * *}$ & $0.11 *$ & -0.09 & -0.03 & $0.18 * *$ \\
\hline Suicidal & $0.05^{* *}$ & -0.12 & $0.16^{* *}$ & $0.23^{* * *}$ & $0.20^{* * *}$ & 0.07 & -0.07 & -0.04 & 0.11 \\
\hline
\end{tabular}




\begin{tabular}{|c|c|c|c|c|c|c|c|c|c|}
\hline Variable & $\begin{array}{l}\text { US Total }^{\mathbf{a}} \\
(\mathrm{n}=3,080)\end{array}$ & $\begin{array}{c}\text { Pacific } \\
(\mathrm{n}=166)\end{array}$ & $\begin{array}{c}\text { Mountain } \\
(\mathrm{n}=274)\end{array}$ & $\begin{array}{c}\text { W. } \\
\text { North } \\
\text { Central } \\
(\mathrm{n}=598)\end{array}$ & $\begin{array}{c}\text { E. North } \\
\text { Central } \\
(\mathrm{n}=431)\end{array}$ & $\begin{array}{c}\text { W. } \\
\text { South } \\
\text { Central } \\
(\mathrm{n}=463)\end{array}$ & $\begin{array}{c}\text { E. South } \\
\text { Central } \\
(n=364)\end{array}$ & $\begin{array}{c}\text { South } \\
\text { Atlantic } \\
(\mathrm{n}=568)\end{array}$ & $\begin{array}{c}\text { Northeast } \\
(\mathrm{n}=216)\end{array}$ \\
\hline $\begin{array}{l}\text { Population } \\
\text { Density }\end{array}$ & $0.31 * * *$ & $0.26 * * *$ & $0.36 * * *$ & $0.38 * * *$ & $0.32 * * *$ & $0.37 * * *$ & $0.27 * * *$ & $0.35^{* * *}$ & $0.16 *$ \\
\hline Anxiety & $0.37 * * *$ & $0.40^{* * *}$ & $0.40^{* * *}$ & $0.43^{* * *}$ & $0.35^{* * *}$ & $0.44^{* * *}$ & $0.30 * * *$ & $0.40^{* * *}$ & $0.21^{* *}$ \\
\hline Depression & $0.35^{* * *}$ & $0.30^{* * *}$ & $0.43^{* * *}$ & $0.40^{* * *}$ & $0.34^{* * *}$ & $0.39^{* * *}$ & $0.27^{* * *}$ & $0.36^{* * *}$ & $0.17^{*}$ \\
\hline Suicidal & $0.32 * * *$ & $0.30^{* * *}$ & $0.37^{* * *}$ & $0.40^{* * *}$ & $0.34^{* * *}$ & $0.41^{* * *}$ & $0.26^{* * *}$ & $0.36^{* * *}$ & 0.12 \\
\hline $\begin{array}{l}\text { Moved in the } \\
\text { Past Year }\end{array}$ & $0.23 * * *$ & $0.18 *$ & $0.32 * * *$ & $0.29 * *$ & $0.28 * * *$ & $0.26 * *$ & $0.23 * * *$ & $0.23^{* * *}$ & $0.21 * *$ \\
\hline Anxiety & $0.23^{* * *}$ & $0.15^{*}$ & $0.15^{*}$ & $0.28^{* * *}$ & $0.27 * * *$ & $0.27^{* * *}$ & $0.26^{* * *}$ & $0.24^{* * *}$ & $0.20 * *$ \\
\hline Depression & $0.22^{* * *}$ & $0.25^{* *}$ & $0.25^{* *}$ & $0.28 * * *$ & $0.30 * * *$ & $0.26^{* * *}$ & $0.23^{* * *}$ & $0.23^{* * *}$ & $0.20 * *$ \\
\hline Suicidal & $0.22 * * *$ & $0.22 * *$ & $0.22 * *$ & $0.28 * * *$ & $0.29 * * *$ & $0.25^{* * *}$ & $0.21^{* * *}$ & $0.23^{* * *}$ & $0.24 * * *$ \\
\hline Rental Homes & $0.24 * * *$ & 0.05 & $0.26 * * *$ & $0.25 * * *$ & $0.39 * * *$ & $0.25 * * *$ & $0.24 * * *$ & $0.24^{* * *}$ & $0.29 * * *$ \\
\hline Anxiety & $0.24^{* * *}$ & 0.05 & $0.26^{* * *}$ & $0.23^{* * *}$ & $0.39 * * *$ & $0.23^{* * *}$ & $0.25^{* * *}$ & $0.25^{* * *}$ & $0.30^{* * *}$ \\
\hline Depression & $0.24 * * *$ & 0.11 & $0.29 * * *$ & $0.24^{* * *}$ & $0.37^{* * *}$ & $0.25^{* * *}$ & $0.21^{* * *}$ & $0.26^{* * *}$ & $0.29 * * *$ \\
\hline Suicidal & $0.24 * * *$ & 0.02 & $0.25^{* * *}$ & $0.22 * * *$ & $0.37 * * *$ & $0.23^{* * *}$ & $0.23 * * *$ & $0.25 * * *$ & $0.27^{* * *}$ \\
\hline
\end{tabular}

\subsubsection{Socioeconomic and Demographic Covariates}

Household mean income, unemployment, and low educational attainment demonstrated small effects on CTL usage at the national scale $\left(\rho=0.14 * * *, 0.09^{* * *}\right.$, and $0.14^{* * *}$, respectively), and none of the socioeconomic indicators were significant for all divisions. At a national level, CTL usage is slightly elevated in counties with higher socioeconomic status. Low correlations with poverty nationally $(\rho=0.01)$ and in the majority of study divisions suggest that CTL usage does not covary with poverty rate at the county level. The detection of even a small socioeconomic effect on CTL is of interest because unlike many mental health services, CTL is available at no cost. However, cell phone ownership among adolescents varies with parental household income, ranging from 69 percent (less than $\$ 30,000 /$ year) to 86 percent ( $\$ 75,000$ or more/year), which may explain some of this relationship (Madden et al., 2013). 
In seven of the eight geographic divisions, counties with higher divorce rates tended to have higher CTL usage, though this relationship was fairly small $\left(\rho=0.17^{* * *}\right)$. Prior research has found increased mental health issues for both divorced individuals (Hempstead, 2006; Akhtar-Danesh and Landeen, 2007) and adolescents with divorced parents (Merikangas et al., 2011). Divorce has also been associated with increased suicide rates at the state and regional level in the U.S. (Barkan et al., 2013).

No relationship was found between a county's racial composition and its CTL usage ( $\rho=0.03$ nationally), with the exception of the two divisions in the Midwest, where effect sizes were small to moderate $\left(\rho=0.19^{* * *}-0.28^{* * *}\right)$. In some divisions, counties with higher Hispanic populations also had higher CTL usage. However, the strongest relationships were found in the midwest (East and West North Central) and southeast (East South Central and South Atlantic), locations with lower Hispanic populations overall, suggesting it is unlikely that the Hispanic population can account for these increased rates. Interpreting racial and ethnic differences in help-seeking is challenging. Suicide rates are substantially higher among non-Hispanic white individuals under age 35 (10.3), than Hispanic or black individuals of the same age (5.3) (CDC, 2016a). However, a survey by the Youth Risk Behavior Surveillance System (grades 9-12), found Hispanic youth were more likely than black or white youth to report feeling sad or hopeless and to report considering, planning, and attempting suicide (CDC, 2016b).

\subsubsection{Residential Instability Covariates}

Counties with increased residential instability tended to have higher rates of CTL use. This was measured by the percent of the population living in a different home during the past 
twelve months $\left(\rho=0.23^{* * *}\right)$ and the percent of renter-occupied homes $\left(\rho=0.24^{* * *}\right)$. The relative strength of these relationships is supported by a recent study in which the authors used similar census variables to explore the relationship between residential stability, population density, and suicide rates (Barkan et al., 2013). Low residential stability partially

explained higher suicide rates in the western U.S. and state suicide rates nationally (Barkan et al., 2013). However in the present study, because younger individuals are both more likely to use CTL and experience residential instability, correlations between residential stability and CTL use may be influenced by a county’s relative age.

\subsubsection{Environmental Covariates}

Correlation coefficients for latitude $\left(\rho=0.15^{* * *}\right)$ and annual mean GHI $(\rho=$ $0.19 * * *)$ are reported for the U.S. as a whole to allow for comparisons between the northernmost and southernmost counties. These variables are highly correlated $(\rho=$ $\left.0.79^{* * *}\right)$, which explains their similar effect sizes. Certain mental health disorders are known to be impacted by seasonality such as winter Seasonal Affective Disorder (SAD). Prevalence of SAD has been associated with northern latitudes (Mersch et al., 1999; Magnusson, 2005) and reduced exposure to light in the winter (Nillni et al., 2009), though little work has been done to explore prevalence of SAD among adolescents (Nillni et al., 2009). In a national survey, no significant differences in prevalence of SAD were observed across latitudes, but parents of adolescents ages sixteen to eighteen reported exacerbated symptoms of depression during winter months (Nillni et al., 2009), which are longer and more severe at higher latitudes. The seasonality of mental health issues is further supported by a recent study that identified significant seasonal trends in Google searches for all mental health issues in the 
U.S. and Australia (Ayers et al., 2013). The observed relationship between GHI, latitude, and CTL use supports future work investigating the relationship between climate, seasonality, and mental health.

\subsubsection{Mental Health Covariates}

Surprisingly, county level suicide rates (1999-2016) demonstrated only a small relationship with CTL use $\left(\rho=0.11^{* * *}\right)$, even among conversations pertaining to suicidal thoughts $\left(\rho=0.10^{* * *}\right)$. To reduce the amount of counties with suppressed suicide rates, data was averaged for all available years (1999-2016). However, when suicide data prior to 2011 was removed, a stronger relationship was measured $(\rho=0.34 * * *)$. Because suicide rates have changed significantly since 1999 (Fontanella et al., 2015), it is likely some of this

change in effect size is due to the use of a more comparable date range. It is also possible rural areas with low counts and less reliable rates could be affecting results. Mental HPSA scores were also explored, but demonstrated no relationship with CTL help-seeking behavior $(\rho=-0.03$ to -0.05$)$. HPSAs may not be representative of shortages in all locations because counties must dedicate time and resources to request and obtain this designation (Parchman and Culler, 1999). Further, hotlines offer a very different service than traditional health professionals, so CTL use may not be reflective of a county’s degree of mental health professional shortage.

\subsubsection{Spatial Error Regression Models}

Results of the final spatial error regression model are shown in Table 5, and are comparable across each issue (anxiety, depression, and suicidal thoughts). The final spatial 
error regression model explains 25 percent, 24 percent, and 23 percent of variance for anxiety, depression, and suicidal thoughts, respectively. A county’s aggregate RUCC code and its percentage of rental homes are the strongest predictors for CTL usage for all three issues.

Table 5. Results of National Spatial Error Regression Analyses

\begin{tabular}{lcccccc}
\hline & \multicolumn{2}{c}{ Anxiety } & \multicolumn{2}{c}{ Depression } & \multicolumn{2}{c}{ Suicidal Thoughts } \\
\hline Pseudo R & \multicolumn{2}{c}{0.25} & \multicolumn{2}{c}{0.24} & \multicolumn{2}{c}{0.23} \\
\hline & z value & Signif. of z & z value & Signif. of z & z value & Signif. of z \\
\hline Mean Household Income & 4.382 & $<0.001$ & 4.058 & $<0.001$ & 3.558 & $<0.001$ \\
Did Not Complete High School & -3.693 & $<0.001$ & -2.894 & 0.004 & -4.274 & $<0.001$ \\
Minority & -6.48 & $<0.001$ & -5.991 & $<0.001$ & -5.362 & $<0.001$ \\
Hispanic & -3.489 & $<0.001$ & -3.819 & $<0.001$ & -2.919 & $<0.01$ \\
Divorced & 4.448 & $<0.001$ & 3.988 & $<0.001$ & 5.543 & $<0.001$ \\
Single Parent Homes & 4.131 & $<0.001$ & 3.894 & $<0.001$ & 3.456 & $<0.001$ \\
2 (RUCC 2 and 3) & 0.619 & 0.536 & 0.455 & 0.649 & 0.437 & 0.662 \\
3 (RUCC 4 and 5) & 5.87 & $<0.001$ & 5.89 & $<0.001$ & 5.891 & $<0.001$ \\
4 (RUCC 6 and 7) & 2.06 & $<0.05$ & 3.208 & $<0.01$ & 2.867 & $<0.01$ \\
5 (RUCC 8 and 9) & -9.246 & $<0.001$ & -9.235 & $<0.001$ & -8.959 & $<0.001$ \\
Rental Homes & 10.589 & $<0.001$ & 10.16 & $<0.001$ & 9.775 & $<0.001$ \\
\hline
\end{tabular}

\subsection{Rural-Urban differences in help-seeking}

Data from CTL provides one of the first opportunities to study the rate of helpseeking for suicidal thoughts across the rural-urban continuum. Counties with higher population density have higher rates of CTL usage ( $\rho=0.31^{* * *}$ nationally), with effect sizes ranging from small to moderate across census divisions $\left(\rho=0.16^{*-}-0.38^{* * *}\right)$. The aggregate RUCC codes explained between 18 and 20 percent of the variance in the final spatial error regression models, more than three-quarters of the total explained variance. The relative 
strength of this relationship suggests rural counties are significantly less likely to engage in text-based help-seeking behavior.

Significant differences were found between rates of help-seeking for suicidal thoughts in non-metro counties (RUCC 4 and 5) and rural counties (RUCC 8 and 9) ( $\alpha=0.01$ ). As shown in Table 6 and Figure 2, rates of help-seeking were significantly higher for non-metro counties and significantly lower for rural counties. Group differences in suicide rates were also significant between all groups except between small metro counties (RUCC 2 and 3) and non-metro counties (RUCC 4 and 5) $(\alpha=0.01)$. When suicide rates are age-adjusted this relationship becomes stronger, and adolescents living in the most rural areas (RUCC 8 and 9) are nearly twice as likely to die by suicide than adolescents in the most urban areas (Fontanella et al., 2015).

Table 6. Suicide Rates and Suicidal Thought Rates for Rural and Urban Counties

\begin{tabular}{|c|c|c|c|c|}
\hline Category & RUCC & Description & $\begin{array}{l}\text { Suicide Rate } \\
\text { Mean }\end{array}$ & $\begin{array}{l}\text { Suicidal Thoughts } \\
\text { Rate Mean }\end{array}$ \\
\hline${ }^{\mathrm{a}}$ Large Metro & 1 & $\begin{array}{l}\text { Counties in metro areas of } 1 \text { million } \\
\text { population or more }\end{array}$ & $12.58^{\text {b,c,d,e }}$ & 24.58 \\
\hline${ }^{\mathrm{b}}$ Small Metro & 2,3 & $\begin{array}{l}\text { Counties in metro areas of few than } 1 \\
\text { million population }\end{array}$ & $13.98^{\mathrm{a}, \mathrm{d}, \mathrm{e}}$ & 26.95 \\
\hline${ }^{\mathrm{c}}$ Non-metro & 4,5 & $\begin{array}{l}\text { Non-metro urban population of } 20,000 \\
\text { or more }\end{array}$ & $14.38^{\mathrm{a}, \mathrm{d}, \mathrm{e}}$ & $33.96^{\mathrm{a}, \mathrm{b}, \mathrm{d}, \mathrm{e}}$ \\
\hline${ }^{\mathrm{d}}$ Semi-Rural & 6,7 & $\begin{array}{l}\text { Non-metro urban population of } 2,500 \\
\text { to } 19,999\end{array}$ & $15.51^{\text {a,b,ce }}$ & 25.95 \\
\hline${ }^{\mathrm{e}}$ Rural & 8,9 & $\begin{array}{l}\text { Completely rural or less than 2,500 } \\
\text { urban population }\end{array}$ & $18.19^{\mathrm{a}, \mathrm{b}, \mathrm{c}, \mathrm{d}}$ & $14.76^{\mathrm{a}, \mathrm{b}, \mathrm{c}, \mathrm{d}}$ \\
\hline
\end{tabular}

a,b,c,d,e Indicates a significant group difference in rate of help-seeking for suicidal thoughts ( $\alpha$ $=0.01$, Dunnett-Tukey-Kramer Pairwise Multiple Comparison Test) 
As shown in Figure 2, county suicide rates consistently increase with rurality. For counties with urban populations greater than 20,000 (RUCC 1-5), rates of help-seeking for suicidal thoughts also increase with rurality, and these rates are substantially higher than suicide rates for most counties in these groups. However, for counties with urban populations below 20,000 (RUCC 6-9), help-seeking rates decrease while suicide rates continue to rise. Approximately half of all semi-rural counties have help-seeking rates at or below most of these same county's suicide rates. For the most rural counties, the median rate of helpseeking for suicidal thoughts falls well below the median suicide rate, suggesting the most rural counties have low rates of help-seeking behavior despite high suicide rates. Figure 5 in the appendix shows this trend is consistent for suicide rates for the portion of a county's population most likely to use CTL (under age 35).

A large portion of the most rural counties have little or no CTL use, resulting in a severely skewed distribution. Among rural counties that have engaged in any CTL conversations ( $n=273,44.5 \%)$, the mean help-seeking rate approximates the mean suicide rate. Substantial within-group variation is apparent across all rural-urban groups.

Figure 3 identifies counties (with any CTL use) where the annual suicide rate exceeds the annual rate of help-seeking for suicidal thoughts. In these counties, where the need for suicide prevention resources is the greatest, CTL is being used at an alarmingly low rate. This disparity is compounded by the fact that many rural areas experience mental health professional shortages (Bird et al., 2001; Health Resources and Services Administration, 2018). Reduced rates of help-seeking in rural counties may not be limited to text-based resources, but across other services as well. 
It is unlikely that rural-urban differences in cell phone ownership alone can explain these findings. Among adults in the U.S., 91 percent own a cell phone, and this number rises to $97 \%$ for adults aged $18-35$ (Rainie, 2013). While ownership rates drop to $85 \%$ for rural individuals (Rainie, 2013), it is reasonable to assume this gap decreases among younger adults in rural areas. Among adolescents aged 12-17, 78\% own a cell phone (Madden et al., 2013). Suburban teens are most likely to own a cell phone (81\%), followed by urban and rural adolescents (76\% and 73\%, respectively). Rural adolescent cell phone ownership is slightly lower, but this difference was not statistically significant (Madden et al., 2013).

To evaluate whether certain locations experienced a greater change in usage over time, percent change was calculated for each county, shown in Figure 4. The primary concern was to evaluate whether rural locations were less likely to adopt CTL to consider whether this may have an effect on observed differences in usage between RUCCs. Population density had a slightly negative correlation with percent change in CTL usage ( $\rho=$ $\left.-0.08^{* * *}\right)$, suggesting there is little difference in uptake in CTL usage and rural or urbanness. Moran’s I test revealed no geographic clustering of percent change across the US (p-value > 0.05). However when tested with counties with no CTL usage, geographic clustering was observed (p-value $<0.001$ ). Clustering was predominately found in locations with a high concentration of rural counties, the western half of the West North Central division, the eastern portion of the Mountain division, and Texas. Smaller significant clusters of counties with low or no percent change were found on the border of Missouri and Illinois and West Virginia. These clusters are only present when counties with no CTL use are included, and thus indicate clusters of rural counties that have never used CTL. 
It is well known that disparities exists in on-the-ground mental health services (e.g., HPSA) (Bird et al., 2001). However, CTL is a remote service unaffected by these traditional geographical barriers. Stigma is known to be a significant barrier to mental health and suicide help-seeking, and some researcher suggests stigma may be more prevalent in rural areas, perhaps exacerbated by limited privacy among small communities (Cantrell et al., 2012; Fontanella et al., 2015). However, CTL counseling is discrete, anonymous, and available 24/7, which should provide a buffer against stigma. Goldman-Mellor et al. found rural California adolescents were significantly less likely to report suicidal ideation and suicide attempts, despite higher rates of suicide (2017). Findings of negative attitudes towards helpseeking for mental health issues and suicide may explain reduced help-seeking among rural communities (Barry et al., 2000; Hirsch, 2006). Low rates of CTL use among rural populations support these findings on a national scale. Whether this disparity is due to cultural factors (i.e., stigma), a lack of advertising in rural areas, or other factors should be the subject of future research.

\subsection{Limitations}

Results of this study are not intended to suggest causality for help-seeking rates, and should not be used to make assumptions at an individual level (i.e., ecological fallacy). The aim of this exploratory study is to identify regional and national trends and generate hypotheses that can be explored in future research at smaller scales. The use of CTL requires access to a mobile device and cellular service, and therefore the sample is likely not representative of all locations and populations. CTL relies upon phone numbers to generate county location, which are not always indicative of residence. However, among adolescents, 
there is a higher likelihood that area code represents actual location. Additionally, CTL usage experiences a dramatic rise in conversation frequency across this study’s four years of data, and more sporadic usage during the first two years. This trend limits the usefulness of earlier years and results in an underestimation of annual rates.

The states of Ohio, California, Montana, Wisconsin, and New Hampshire have statelevel partnerships with CTL. These partnerships may introduce noise that may obscure other variables. The authors also acknowledge that, in many rural counties, CTL usage rates are based on low conversation counts and may be unreliable. However, the power of this study is its recognition of these extremely low counts and rates, and results call for future research to investigate underlying causal mechanisms.

\section{Conclusions}

CTL is an important and widely-used support tool for mental distress among adolescents. Findings from this study indicate county-level variation in help-seeking behavior associated with several county characteristics. Increased rates of CTL usage occur in counties with higher mean household incomes, higher divorce rates, and lower residential stability. However, findings from this study suggest that despite the availability of a new, ubiquitous, text-based model of crisis support traditionally underserved populations fail to utilize this resource at expected rates. Particularly concerning is the finding that underserved

rural, isolated populations, despite having very similar rates of cell phone ownership as urban populations, are still much less likely to engage in help-seeking behavior through CTL. This lack of help-seeking behavior among rural populations compounds ongoing disparities in traditional mental health treatment services for this population. Further, this finding suggests 
that increased suicide risk in rural areas cannot be explained by mental health professional shortages or access to lethal means alone, and may be the result of cultural differences, a lack of advertising, or another factor. Rural communities, particularly those with low help-seeking behavior and comparatively high suicide rates should be the target of future research and outreach.

\section{Acknowledgements}

Health data was supplied by Crisis Text Line. Crisis Text Line does not take responsibility for the scientific validity or accuracy of methodology, results, statistical analyses, or conclusions presented. The authors thank Bob Filbin and Nitya Kanuri for providing Crisis Text Line data and approving outputs for research use. This work would not be possible without their support. 


\section{References}

Akhtar-Danesh N., Landeen, J., 2007. Relation between depression and sociodemographic factors. International Journal of Mental Health Systems 1(1), 4. http://doi.org/10.1186/1752-4458-1-4

Alegria, M., Green, J.G., Mclaughlin, K.A. and Loder, S., 2015. Disparities in Child and Adolescent Mental Health and Mental Health Services in the US. William T. Grant Foundation: 1-26.

Amone-P’Olak, K., Burger, Ormel, J. M. Huisman, M. Verhulst, and Oldehinkel, A.J., 2009. Socioeconomic Position and Mental Health Problems in Pre- and Early-Adolescents: The Trails Study. Social Psychiatry and Psychiatric Epidemiology 44(3), 231-38. doi:10.1007/s00127-008-0424-z.

Ayers, J. W., Althouse, B.M., Allen, J.P., Rosenquist, J.N., and Ford, D.E., 2013. Seasonality in seeking mental health information on Google. American Journal of Preventive Medicine 44(5), 520-525. http://doi.org/10.1016/j.amepre.2013.01.012

Ayers, J.W., Althouse, B.M., and Dredze M., 2014. Could Behavioral Medicine Lead the Web Data Revolution? 92123: 7-8. doi:10.1001/jama.2014.1505.

Ayers, J.W., Althouse, B.M., Leas, E.C., Dredze, M., and Allem, J.P., 2016. Internet Searches for Suicide Following the Release of 13 Reasons Why. Implementation Science 11(1), 1527-29. doi:10.1186/s13012-016-0390-x.

Baller, R.D, and Richardson, K.K., 2016. Social Integration, Imitation, and the Geographic Patterning of Suicide. American Sociological Association 67(6), 873-88.

Barkan, S.E, Rocque, M., and Houle, J., 2013. State and Regional Suicide Rates: A New Look at an Old Puzzle. Sociological Perspectives 56 (2), 287-97. doi:10.1525/sop.2013.56.2.287.

Barry, M.M., Doherty, A., Hope, A., Sixsmith, J., and Kelleher, C.C., 2000. A community needs assessment for rural mental health promotion. Health Education Research, Theory and Practice 15(3), 293-304. http://doi.org/10.1093/her/15.3.293

Batterham, P.J., Calear, A.L., and Christensen, H., 2013. Correlates of suicide stigma and suicide literacy in the community. Suicide and Life-Threatening Behavior, 43(4), 406-417. http://doi.org/10.1111/sltb.12026)

Bird, D., Dempsey, P., and Hartley, D., 2001. Addressing Mental Health Workforce Needs in Underserved Rural Areas: Accomplishments and Challenges. Accessed from http://citeseerx.ist.psu.edu/viewdoc/download?doi=10.1.1.551.6793andrep=rep1andty pe=pdf (last accessed 30 March 2018). 
Breslau, J., Marshall, G.N., Pincus, H.A., and Brown, R.A., 2014. Are Mental Disorders More Common in Urban than Rural Areas of the United States? Journal of Psychiatric Research, 56, 50-55. doi:10.1016/j.jpsychires.2014.05.004.

Burns, B.J., Costello, E.J., Angold, A., Tweed, D., Stangl, D., Farmer, E.M.Z., and Erkanli, A., 1995. Children's mental health service use across service sectors. Health Affairs, 14(3), 147-159. http://doi.org/10.1377/hlthaff.14.3.147

Cantrell, C., Valley-Gray, S., Cash, R.E. Suicide in rural areas: Risk factors and prevention. In: Smalley, K.B.,Warren, J.C., Rainer, J.P., eds. Rural Mental Health. New York, NY: Springer, 2012: 213-228.

Center for Behavioral Health Statistics and Quality, 2016. 2016 National Survey on Drug Use and Health: Detailed Tables. Substance Abuse and Mental Health Services Administration, Rockville, MD. Accessed from https://www.samhsa.gov/data/sites/default/files/NSDUH-DetTabs-2016/NSDUHDetTabs-2016.htm\#tab9-1B (last accessed 5 December 2017).

Centers for Disease Control and Prevention, National Center for Injury Prevention and Control, 2016a. Web-based Injury Statistics Query and Reporting System (WISQARS). http://www.cdc.gov/injury/wisqars. (accessed 26 February 2018).

Centers for Disease Control and Prevention, 2016b. Youth Risk Behavior Surveillance System (YRBSS). Division of Adolescent and School Health. Accessed from https://www.cdc.gov/ healthyyouth/data/yrbs/index.htm (last accessed 26 February 2018).

Costello, E.J., He, J., Sampson, N.A., Kessler, R.C., and Merikangas, K.R., 2014. Services for Adolescents With Psychiatric Disorders: 12-Month Data From the National Comorbidity Survey-Adolescent. Psychiatric Services, 65(3), 359-366. http://doi.org/10.1176/appi.ps.201100518

Cutchin, M.P., and Churchill, R.R., 1999. Scale, Context, and Causes of Suicide in the United States. Social Science Quarterly, 80(1), 97-114.

http://doi.org/10.2307/42863876

De Choudhury, M., Counts, S., and Horvitz, E., 2013. Social Media as a Measurement Tool of Depression in Populations. WebSci '13 Proceedings of the 5th Annual ACM Web Science Conference, 47-56. http://doi.org/10.1145/2464464.2464480

Deisenhammer, E.A., Ing, C.M., Strauss, R., Kemmler, G., Hinterhuber, H., and Weiss, E.M., 2009. The duration of the suicidal process: How much time is left for intervention between consideration and accomplishment of a suicide attempt? Journal of Clinical Psychiatry 70(1), 19-24. http://doi.org/10.4088/JCP.07m03904 
Durkheim, E. [1897] 1951. Suicide. London, England: Routledge.

Erceg-Hurn, D.M., and Mirosevich, V.M., 2008. Modern Robust Statistical Methods: An Easy Way to Maximize the Accuracy and Power of Your Research. American Psychologist, 63(7), 591-601. doi:10.1037/0003-066X.63.7.591.

Evans, W. P., Davidson, L., and Sicafuse, L., 2013. Someone to listen: Increasing youth help-seeking behavior through a text-based crisis line for youth. Journal of Community Psychology, 41(4), 471-487. http://doi.org/10.1002/jcop.21551

Fontanella, C.A., Hiance-Steelesmith, D.L., Phillips, G.S., Bridge, J.A., Lester, N., Sweeney, H.A., and Campo, J.V., 2015. Widening rural-urban disparities in youth suicides, United States, 1996-2010. JAMA Pediatrics, 169(5), 466-473. http://doi.org/10.1001/jamapediatrics.2014.3561

Galea, S., Uddin, M., and Koenen, K., 2011. The Urban Environment and Mental Disorders Epigenetic Links. Epigenetics 64,400-404. doi:10.4161/epi.6.4.14944.

Goldman-Mellor, S., Allen, K., and Kaplan, M.S., 2017. Rural/Urban Disparities in Adolescent Nonfatal Suicidal Ideation and Suicide Attempt: A Population-Based Study. Suicide and Life-Threatening Behavior [serial online]. http://doi.org/10.1111/sltb.12390

Gould, M.S., Kalafat, J., HarrisMunfakh, J.L., and Kleinman, M., 2007. An Evaluation of Crisis Hotline Outcomes Part 2: Suicidal Callers. Suicide and Life-Threatening Behavior 37(3), 338-352. http://doi.org/10.1521/suli.2007.37.3.338

Gunn, J. F., and Lester, D., 2013. Using google searches on the internet to monitor suicidal behavior. Journal of Affective Disorders 148(2-3), 411-412. http://doi.org/10.1016/j.jad.2012.11.004

Haner, D., and Pepler, D., 2016. "Live chat” clients at kids help phone: Individual characteristics and problem topics. Journal of the Canadian Academy of Child and Adolescent Psychiatry 25(3), 138-144.

[dataset] Health Resources and Services Administration, U.S. Department of Health and Human Services, 2018. Mental Health Professional Shortage Areas, Parent Boundaries. Accessed from https://datawarehouse.hrsa.gov/data/datadownload.aspx (last accessed 1 February 2018).

Hempstead, K., 2006. The geography of self-injury: Spatial patterns in attempted and completed suicide. Social Science and Medicine, 62(12), 3186-3196. http://doi.org/10.1016/j.socscimed.2005.11.038 
Hirsch, J. K., 2006. A review of the literature on rural suicide: Risk and protective factors, incidence, and prevention. Crisis 27(4), 189-199. http://doi.org/10.1027/0227$\underline{5910.27 .4 .189}$

Jashinsky, J., Burton, S.H., Hanson, C.L., West, J. Giraud-Carrier, C., Barnes, M.D., and Argyle, T., 2014. Tracking suicide risk factors through Twitter in the US. Crisis 35(1): 51-59. http://doi.org/10.1027/0227-5910/a000234

Kalafat, J., Gould, M.S., HarrisMunfakh, J.L., and Kleinman, M., 2007. An Evaluation of Crisis Hotline Outcomes Part 1: Nonsuicidal Crisis Callers. Suicide and LifeThreatening Behavior 37(3), 322-337. http://doi.org/10.1521/suli.2007.37.3.338

Kessler, R.C., Berglund, P., Demler, O., Jin, R., Merikangas, K.R., and Walters, E.E., 2005. Lifetime Prevalence and Age-of-Onset Distributions of DSM-IV Disorders in the National Comorbidity Survey Replication. Archives of General Psychiatry 62(June), 593-602. http://doi.org/10.1001/archpsyc.62.6.593

Kids Count Data Center, 2017. Children in Poverty by Race and Ethnicity. http://datacenter.kidscount.org/data/tables/44-children-in-poverty-by-race-andethnicity?loc=1 andloct=2\#detailed/1/any/false/870,573/10,11,9,12,1,185,13/324,323 (accessed 26 September 2017).

Kovach, M.M., Konrad, C.E., and Fuhrmann, C.M., 2015. Area-Level Risk Factors for HeatRelated Illness in Rural and Urban Locations across North Carolina, USA. Applied Geography 60(June), 175-83. doi:10.1016/j.apgeog.2015.03.012.

Lau, M.K., 2013. DTK: Dunnett-Tukey-Kramer Pairwise Multiple Comparison Test Adjusted for Unequal Variances and Unequal Sample Sizes. R package version 3.5. https://CRAN.R-project.org/package=DTK

Lester, D., and Rogers, J.R., 2012. Crisis intervention and counseling by telephone and the Internet. Springfield, Illinois: Charles C. Thomas.

Madden, M., Lenhart, A., Duggan, M., Cortesi, S., and Gasser, U., 2013. Teens and Technology 2013. Pew Internet and American Life Project, March 13, 2013. http://www.pewinternet.org/Reports/2013/Teens-and-Tech.aspx (accessed on 2 March 2018).

Magnusson, A., 2005. The diagnosis, symptomatology, and epidemiology of Seasonal Affective Disorder. CNS Spectrums 10, 625-634.

Mclaughlin, K.A., Breslau, J., Greif Green, J., Lakoma, M.D., Sampson, N.A., Zaslavsky, A.M., and Kessler, R.C., 2011. Childhood socio-economic status and the onset, persistence, and severity of DSM-IV mental disorders in a US national sample. Social Science and Medicine, 73, 1088-1096. http://doi.org/10.1016/j.socscimed.2011.06.011 
Mersch, P.P.A., Middendorp, H.M., Bouhuys, A.L., Beersma, D.G.M., van den Hoofdakker, R.H., 1999. Seasonal affective disorder and latitude: a review of the literature. Journal of Affective Disorders 53, 35-48.

Merikangas, K. R., He, J.P., Burstein, M. E., Swendsen, J., Avenevoli, S., Case, B., Georgiades, K., Heaton, L., Swanson, S., and Olfson, M., 2011. Service Utilization for Lifetime Mental Disorders in U.S. Adolescents: Results of the National Comorbidity Survey Adolescent Supplement (NCS-A) HHS Public Access. J Am Acad Child Adolesc Psychiatry, 50(1), 32-45. http://doi.org/10.1016/j.jaac.2010.10.006

Messer, L.C, Laraia, B.A., Kaufman, J.S., Eyster, J., Holzman, C., Culhane, J., Elo, I, Burke, J.G., and O’Campo, P., 2006. The Development of a Standardized Neighborhood Deprivation Index. Journal of Urban Health 83(6), 1041-62. doi:10.1007/s11524006-9094-X.

Mishara, B.L., and Daigle, M., 2000. Helplines and crisis intervention services: Challenges for the future. D. Lester (Ed.), Suicide prevention: Resources for the millennium, 153-171. Philadelphia: Brunner-Routledge.

National Advisory Committee on Rural Health and Human Services, 2010. The 2010 Report to the Secretary: Rural Health and Human Services Issues. Rockville, MD: Office of Rural Health Policy, Health Resources and Services Administration, Health and Human Services.

[dataset] National Renewable Energy Laboratory, 2012. Annual Average Global Horizontal Solar Resource Shapefile for the Lower 48 and Hawaii, 10-km Resolution, 19982009. https://www.nrel.gov/gis/data-solar.html (accessed 27 February 2018).

Nestor, B.A., Cheek, S.M., and Liu, R.T., 2016. Ethnic and racial differences in mental health service utilization for suicidal ideation and behavior in a nationally representative sample of adolescents. Journal of Affective Disorders, 202, 197-202. http://doi.org/10.1016/j.jad.2016.05.021

Nillni, Y.I., Rohan, K.J., Rettew, D., and Achenbach, T.M., 2009. Seasonal trends in depressive problems among United States children and adolescents: A representative population survey. Psychiatry Research, 170(2-3), 224-228. http://doi.org/10.1016/j.psychres.2008.07.011

Parchman, M.L. and Culler, S.D., 1999. Preventable hospitalizations in primary care shortage areas: An analysis of vulnerable Medicare beneficiaries. Archives of Family Medicine 8, 487-491. 
Peen, J., Schoevers, R.A., Beekman, A.T., and Dekker J., 2010. The Current Status of UrbanRural Differences in Psychiatric Disorders. Acta Psychiatrica Scandinavica 121(2), 84-93. doi:10.1111/j.1600-0447.2009.01438.x.

Probst, J.C, Laditka, S.B., Moore, C.G., Harun, N. Powell, M.P., and Baxley, E.G., 2006. Rural-Urban Differences in Depression Prevalence: Implications for Family Medicine. Health Services Research 38(9), 653-60.

Rainie, L., 2013. Cell Phone Ownership Hits 91 Percent of Adults. PEW Research Center. http://www.pewresearch.org/fact-tank/2013/06/06/cell-phone-ownership-hits-91-ofadults/ (accessed 13 February 2018).

R Core Team, 2016. R: A language and environment for statistical computing. R Foundation for Statistical Computing, Vienna, Austria, https://www.R-project.org/.

Reiss, F., 2013. Socioeconomic Inequalities and Mental Health Problems in Children and Adolescents: A Systematic Review. Social Science and Medicine 90, 24-31. doi:10.1016/j.socscimed.2013.04.026.

RStudio Team, 2016. RStudio: Integrated Development for R. RStudio, Inc., Boston, MA, http://www.rstudio.com/.

Revelle, W., 2017 psych: Procedures for Personality and Psychological Research, Northwestern University: Evanston, Illinois. https://CRAN.Rproject.org/package=psych Version 1.7.8.

Sen, B., 2004. Adolescent propensity for depressed mood and help seeking: Race and gender differences. Journal of Mental Health Policy and Economics 7(3), 133-145.

Smith, K.B., Humphreys, J.S., and Wilson, M.G.A., 2008. Addressing the Health Disadvantage of Rural Populations: How Does Epidemiological Evidence Inform Rural Health Policies and Research? Australian Journal of Rural Health 16(2), 56-66. doi:10.1111/j.1440-1584.2008.00953.x.

Spady, D.W., Schopflocher, D.P., Svenson, L.W., and Thompson, A.H., 2001. Prevalence of Mental Disorders in Children Living in Alberta, Canada, as Determined from Physician Billing Data. Archives of Pediatrics and Adolescent Medicine 155(10), 1153-59.

Sueki, H., 2011. Does the volume of Internet searches using suicide-related search terms influence the suicide death rate: Data from 2004 to 2009 in Japan. Psychiatry and Clinical Neurosciences, 65(4), 392-394. http://doi.org/10.1111/j.1440$\underline{1819.2011 .02216 . x}$ 
[dataset] U.S. Census Bureau, Selected Population and Housing Characteristics, 2010. Accessed from https://factfinder.census.gov/faces/nav/jsf/pages/index.xhtml (last accessed 1 December 2017).

[dataset] U.S. Census Bureau, American Community Survey, 5-year estimates, 2015. Accessed from https://factfinder.census.gov/faces/nav/jsf/pages/index.xhtml (last accessed 1 December 2017).

[dataset] U.S. Census Bureau, TIGER/Line Shapefiles: Counties (and equivalent), 2017. Accessed from https://www.census.gov/cgi-bin/geo/shapefiles/index.php (last accessed 1 December 2017).

[dataset] U.S. Department of Agriculture, Rural-Urban Contiuum Codes, 2013. Accessed from https://www.ers.usda.gov/data-products/rural-urban-continuum-codes/ (last accessed 1 December 2017).

VanderWielen, L. M., Gilchrist, E. C., Nowels, M. A., Petterson, S. M., Rust, G., and Miller, B. F., 2015. Not Near Enough: Racial and Ethnic Disparities in Access to Nearby Behavioral Health Care and Primary Care. Journal of Health Care for the Poor and Underserved, 26(3), 1032-1047. http://doi.org/10.1353/hpu.2015.0083.

Wang, P.S., Lane, M., Olfson, M., Pincus, H.A., Wells, K.B., and Kessler, R.C., 2016.

Twelve-Month Use of Mental Health Services in the United States. Arch Gen

Psychiatry, 62(June 2005), 629-640. http://doi.org/10.1001/archpsyc.62.6.629

Williams, D.R. and Earl T.R., 2007. Commentary: Race and Mental Health-More Questions than Answers. International Journal of Epidemiology 36(4), 758-60. doi:10.1093/ije/dym114.

World Health Organization, 2001. The World Health Report 2001, Mental Health: New Understanding, New Hope. Geneva: World Health Organization.

Yang, A.C., Tsai, S.J., Huang, N.E., and Peng, C.K., 2011. Association of Internet search trends with suicide death in Taipei City, Taiwan, 2004-2009. Journal of Affective Disorders 132, 179-184. 
Figures with captions

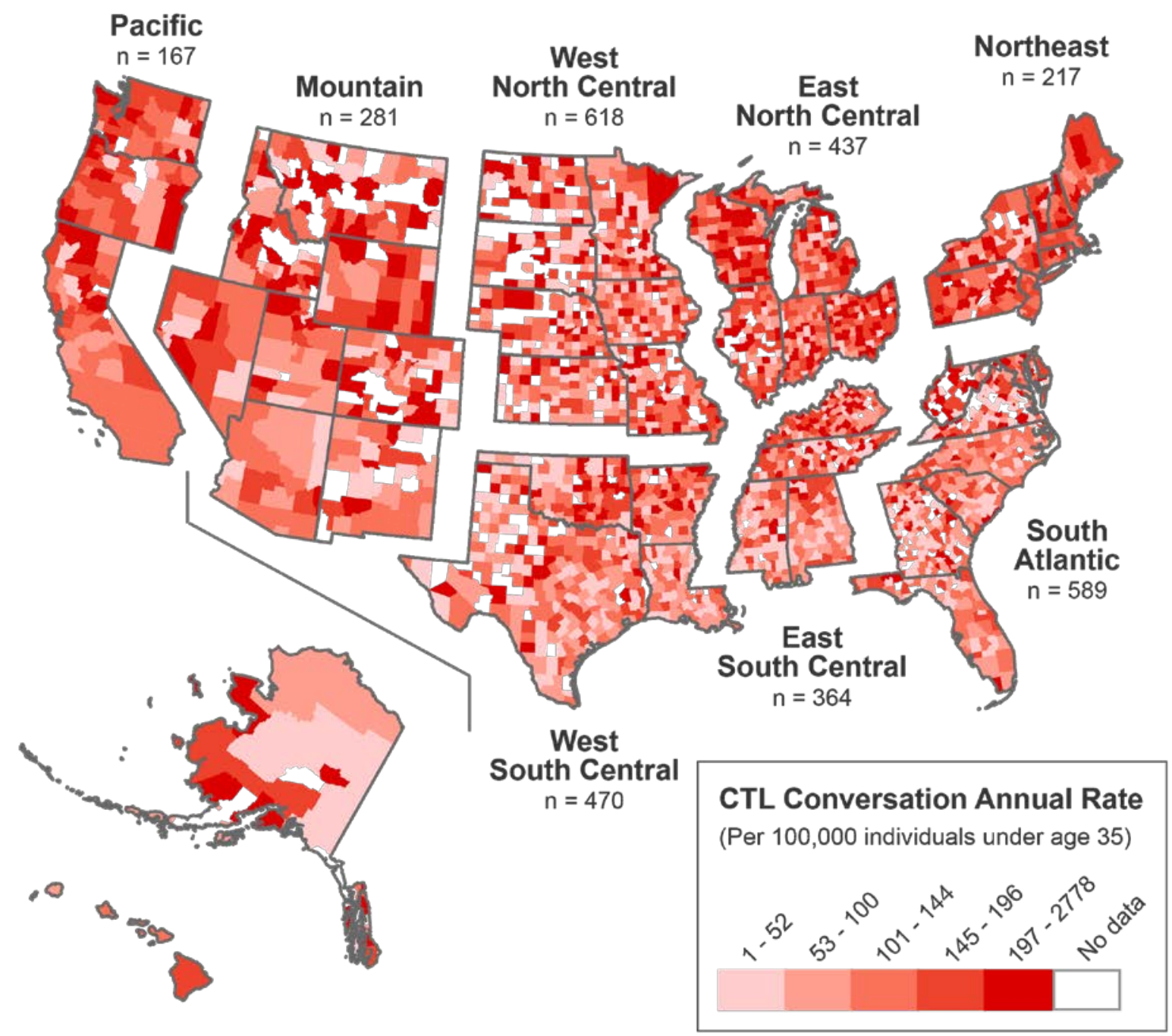

Figure 1. CTL conversation annual rate by county, grouped by U.S. Census division. The Northeast region was not split by division (quantile breaks). 


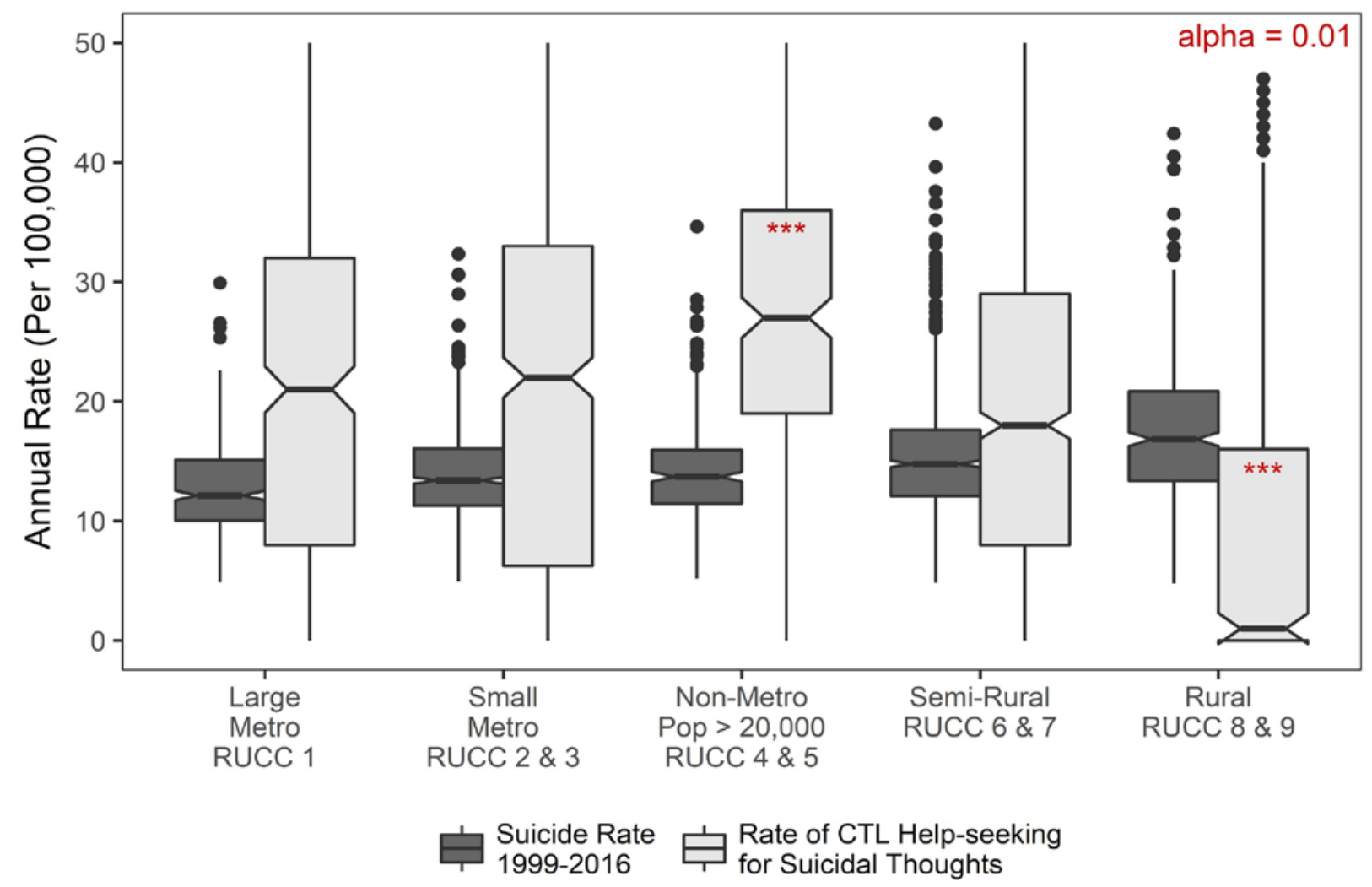

Figure 2. Boxplot of annual suicide rate compared to help-seeking for suicidal thoughts by RUCC. 


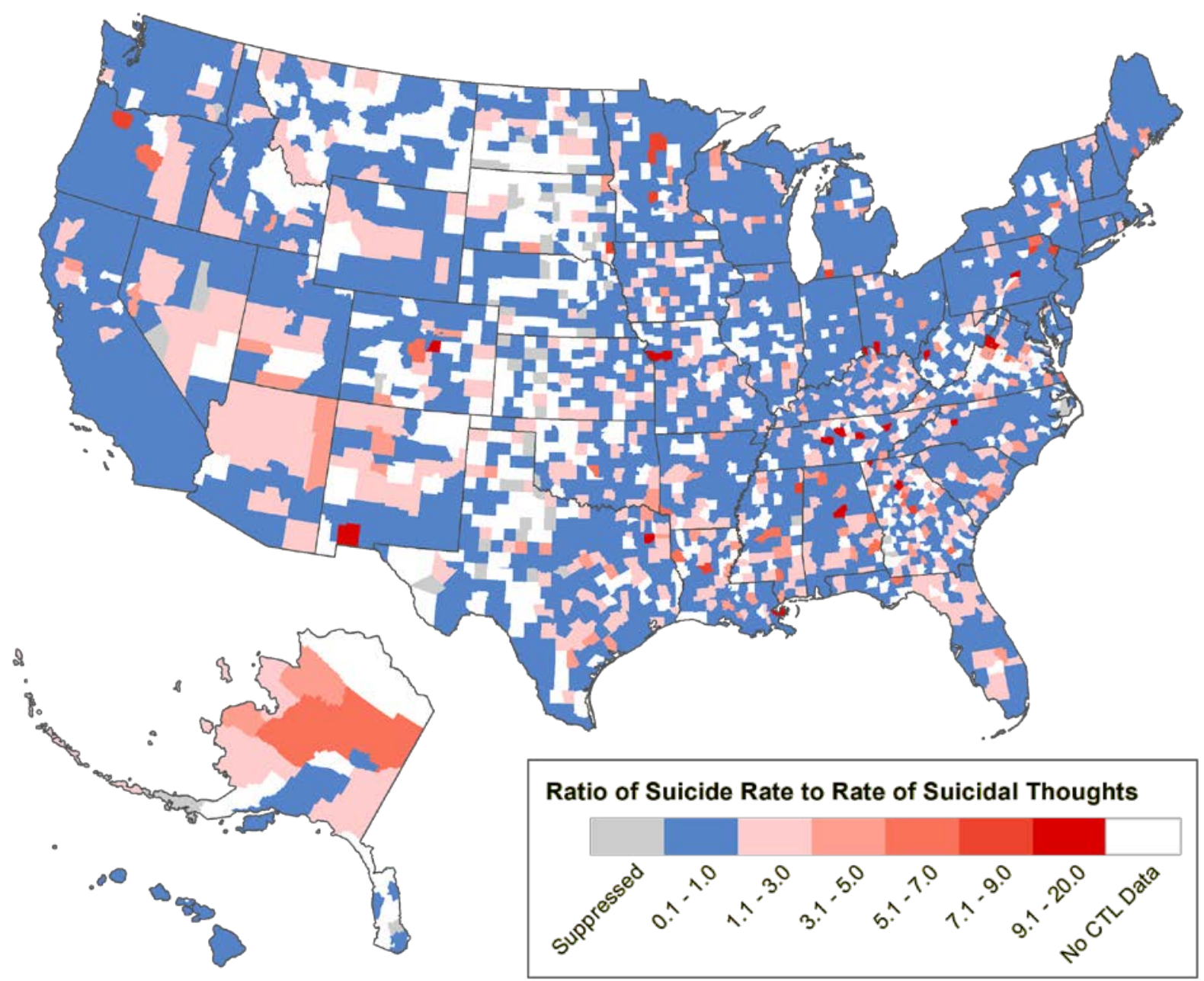

Figure 3. Ratio of annual rate of suicide to annual rate of help-seeking for suicidal thoughts 


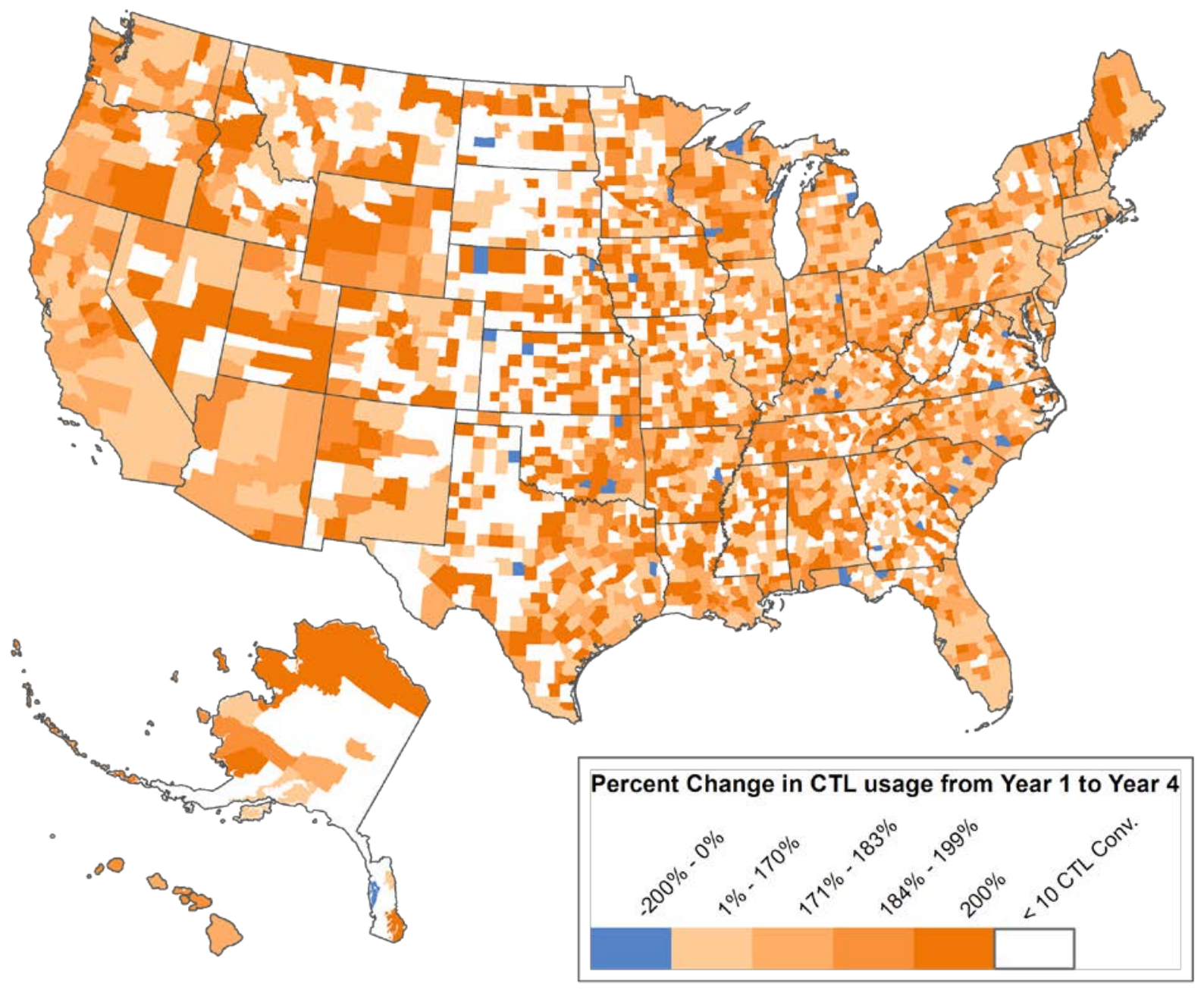

Figure 4. Percent Change in CTL annual conversation rate between August 2013 and July 2017 (Quantile Breaks) 


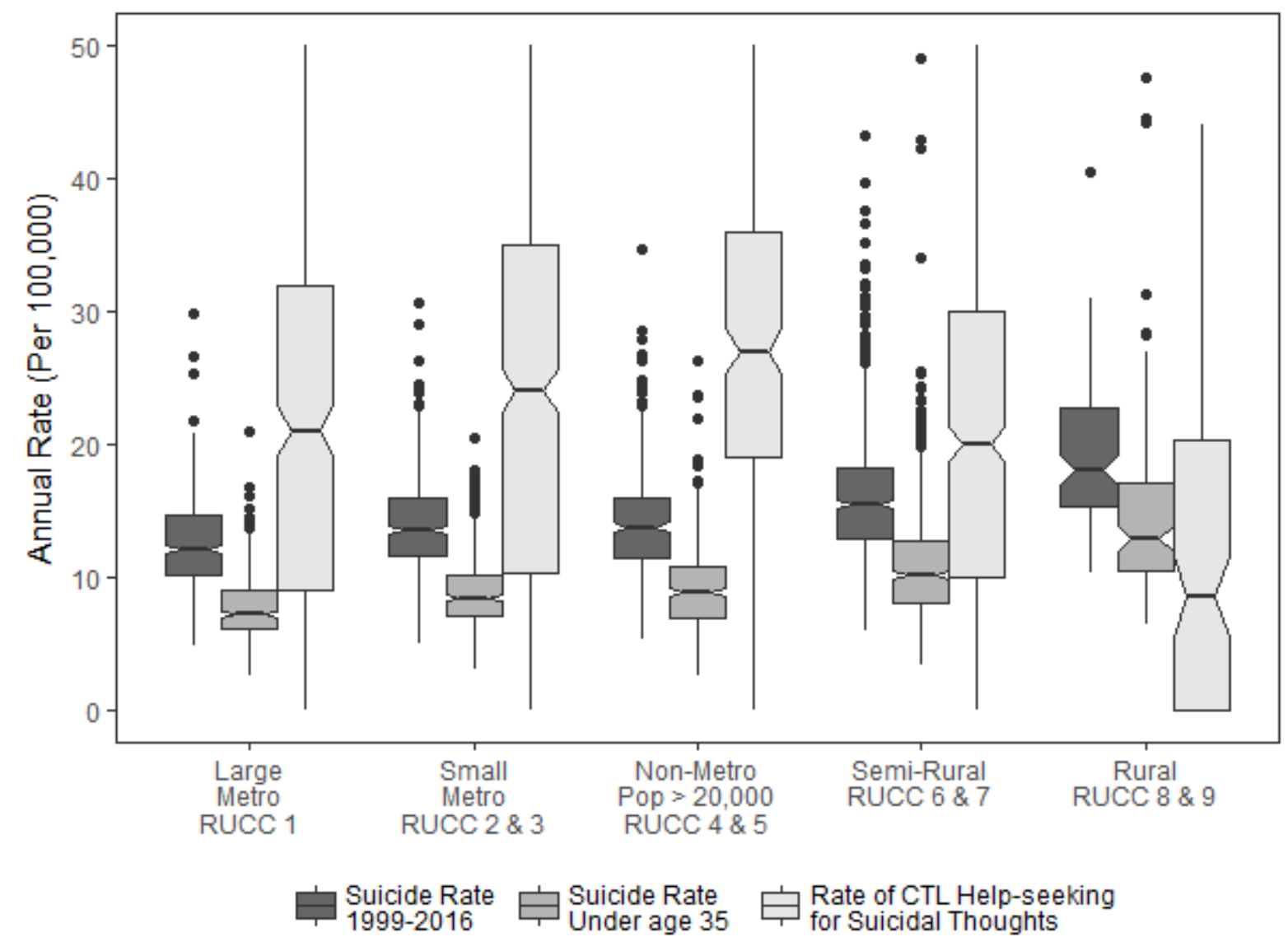

Figure 5. Boxplot of annual suicide rate for the total population and the under 35 population, compared to help-seeking for suicidal thoughts by RUCC. Because this age-based subset of the population results in a suppression of rates for an additional 880 counties with low counts of suicide, and because 489 of these additional suppressed rates are from counties with RUCCs 8 and 9, suicide rates for the total population were used, and this figure is supplied for reference only. 


\section{Vita}

Laura Katherine Thompson grew up Knoxville, Tennessee. Her parents, Bill and Suzan Thompson were dedicated to providing as many opportunities as possible for Laura and her two younger sisters. Laura graduated from Bearden High School in 2007 and began her studies at the University of Tennessee that fall. Laura was always fascinated by social sciences and wanted to study Anthropology since visiting museums with her parents in elementary school. Ultimately, Laura would pursue dual degrees in Anthropology and Studio Art. After graduating in 2011, Laura accepted an AmeriCorps position as an afterschool program coordinator for an elementary school in Boulder County, Colorado, where she fell in love with the mountains. After working in Boulder for three more years, Laura would return to school to pursue a graduate degree in Geography, where she could study social sciences, learn quantitative methods, and incorporate her visual design skills in the presentation of data and maps. Laura was drawn to Appalachian State to be closer to home and remain in the mountains, but most importantly because of the conversations she had with Dr. Baker Perry, Dr. Maggie Sugg, Dr. Elizabeth Shay, and Dr. Kara Dempsey. Over the next year, Laura was surprised to find herself increasingly interested in health geography, and when Dr. Sugg was selected to receive data from Crisis Text Line, Laura was excited to adopt this data for her thesis research. Laura could easily spend the next several years continuing to explore this vast and novel dataset, and is planning to pursue a career in public health research studying behavioral health and contributing to the identification and elimination of health disparities. 